\title{
The Vorticity Budgets of North Atlantic Winter Extratropical Cyclone Life Cycles in MERRA Reanalysis. Part I: Development Phase*
}

\author{
ROOHOLlaH AZAD \\ Geophysical Institute, University of Bergen, Bergen, Norway \\ ASGEIR SORTEBERG \\ Geophysical Institute, and Bjerknes Centre for Climate Research, University of Bergen, Bergen, Norway
}

(Manuscript received 30 August 2013, in final form 21 May 2014)

\begin{abstract}
This series of papers (parts I and II) examines the vorticity budgets of winter North Atlantic extratropical cyclones during the period 1979-2009 using the Modern-Era Retrospective Analysis for Research and Application (MERRA). The authors use a new partitioning technique to combine the Zwack-Okossi (Z-O) equation with the omega equation. The combination provides a possibility to partition the adiabatic term in the $\mathrm{Z}-\mathrm{O}$ equation into its different forcing mechanisms. Thus, both the direct effect of the dynamic and thermodynamic forcings and their indirect effect on the adiabatic term can be calculated to provide the total effect (direct plus indirect) on the 950 -hPa geostrophic vorticity tendency.

It is demonstrated that the total-effect diagnostic is a suitable tool to identify the dynamically consistent characteristics of cyclone development in midlatitudes because it possesses less case-to-case variability. The authors found that the vorticity advection is the major forcing process, the tendencies attributed to the ageostrophic vorticity tendency term are considerable, and the opposing effect of the friction term in moderating the deepening is significant. In general, the upper-level dynamics drive the deepening of the cyclones, except at the end of development, where a combination of midlevel latent heating, positive ageostrophic vorticity tendency, and positive indirect effect of vorticity advection contribute to the development. Additionally, the total effects of temperature advection and latent heating on the intensification of cyclones are reduced because of the inclusion of counteractive indirect effects, as are their variabilities within the cyclone composite.
\end{abstract}

\section{Introduction}

Physical processes responsible for the development of cyclonic disturbances in midlatitudes create a thermal wind imbalance in the geostrophic flow, which consequently provokes ageostrophic motions to restore balance. This produces divergence-convergence through

\footnotetext{
* Supplemental information related to this paper is available at the Journals Online website: http://dx.doi.org/10.1175/JAS-D13-0267.s1.

Corresponding author address: Roohollah Azad, Geophysical Institute, University of Bergen, Allegaten 70, 5007 Bergen, Norway.

E-mail: roohollah.azad@gfi.uib.no
}

the entire depth of the troposphere and lower stratosphere. Induced vertical motion and associated low-level convergence force near-surface cyclonic vorticity. Budgets of near-surface cyclonic vorticity can be determined by including the contributions from forcing mechanisms at each pressure level. The composite budgets of near-surface cyclonic geostrophic vorticity $(\mathrm{CGV})$ and the variability of these values for intense extratropical cyclones (ETCs) over the North Atlantic are the subject of this paper and an accompanying paper on the decaying phase (Azad and Sorteberg 2014, hereafter Part II).

Zwack and Okossi (1986) presented a methodology [the Zwack-Okossi ( $\mathrm{Z}-\mathrm{O})$ equation] to diagnose the surface development by examining the near-surface geostrophic vorticity $(\mathrm{GV})$. Their methodology permits 
explicit consideration of both dynamic and thermal forcing mechanisms at all atmospheric levels. As a modification to the quasigeostrophic $\mathrm{Z}-\mathrm{O}$ equation, Lupo et al. (1992) derived a generalized and simplified form of the development equation and applied it to two ETCs that exhibited explosive development over the southeastern United States and over the Gulf Stream off the coast of New England. Their results demonstrated the utility of the $\mathrm{Z}-\mathrm{O}$ development equation to diagnose synopticscale processes that contribute to the GV tendency near the surface.

The Z-O equation has been successfully applied in many recent studies on ETCs (e.g., Rausch and Smith 1996; Rolfson and Smith 1996; Vasilj and Smith 1997; Walthorn and Smith 1998; Strahl and Smith 2001; Morris and Smith 2001; Parsons and Smith 2004; Yoshida and Asuma 2004; Azad and Sorteberg 2009; KuwanoYoshida and Enomoto 2013). These studies confirm that the major synoptic-scale processes typically controlling the development of ETCs are 1) upper-level cyclonic absolute vorticity advection, 2) lower- and upper-level warm-air advection, and 3) midtropospheric release of latent heat. A review of these papers reveals that the sign and magnitude of contributions vary from case to case. Processes in the boundary layer, such as friction and sensible heating, affect the near-surface vorticity, but their contributions are one order of magnitude smaller than other forcing mechanisms. Subsynopticscale processes can also make important contributions to ETC development by interacting with synoptic-scale processes (Rausch and Smith 1996; Parsons and Smith 2004). Further, some cyclones may not have some of these processes: for example, low-level warm-air advection. Also, in the case of lee cyclogenesis, diabatic warming may be a key ingredient, and sensible heating may not always have such a minor influence over marine surfaces. In the study of Rolfson and Smith (1996), a composite of 12 land cyclone cases over the United States was examined. Their results show that cyclonic vorticity advection was the primary contributor to cyclone development, regardless of the stage of development. They found that, in the more intense stages, the ascending vertical motions forced adiabatic cooling that moderated the development. The adiabatic cooling has always been considered as a forcing mechanism in the Z-O equation. Räisänen (1997) presents an approach for eliminating vertical motions as an independent forcing agent in the vorticity equation by means of the generalized omega equation. This approach allows for dividing the contributions of vorticity advection and friction into parts associated with the direct forcing and the indirect forcing of vertical motion.
The present study addresses two main questions. First, what are the composite effects of physical processes contributing to the development of largescale winter extratropical cyclones over the North Atlantic Ocean? Second, what important insights are gained by partitioning of the $\mathrm{Z}-\mathrm{O}$ forcing terms by means of the omega equation? Compositing highlights the common features of the vorticity budgets of low pressure systems and provides further insight into the relative importance and case-to-case variability of well-established forcing mechanisms. However, a composite analysis can only identify the general structures of cyclones and removes the detailed characteristics of individual events. Partitioning of $\mathrm{Z}-\mathrm{O}$ forcing terms illuminates the efficiency of vertical motions induced by each term in suppressing the development. It also provides the total (direct plus indirect) effect of $\mathrm{Z}-\mathrm{O}$ forcing terms in generating or dissipating cyclonic geostrophic vorticity. Part I of this study describes the methodology, numerical features, and analysis of the composite results for the developing phase of the cyclone life cycle. Part II presents the composite analysis of the $\mathrm{Z}-\mathrm{O}$ forcing terms for the decaying stage of the ETC life cycle. The next section describes the diagnostic equations and the paired form of the $\mathrm{Z}-\mathrm{O}$ and omega equations used to analyze the direct effect of the dynamical and thermodynamical forcing, indirect effect of the adiabatic term, and total contributions to the composite low pressure systems. Section 3 presents the numerical methods applied to estimate tendencies and the vertical motion field. The accuracy of the calculations is then examined in section 4. Additionally, the effect of cyclone movement on the tendency quantities in the cyclone domain and the procedure to remove noisy features are presented in this section. Composite results for the development phase are presented in section 5. Finally, results are summarized and discussed in section 6.

\section{Diagnostic equations}

\section{a. Z-O equation}

The primary diagnostic tool in our composite study is the generalized form of the $\mathrm{Z}-\mathrm{O}$ equation, which is a vorticity tendency equation obtained by coupling the vorticity and the thermodynamic equations through the hydrostatic approximation. The $\beta$ term is neglected because it is one order of magnitude smaller than other vorticity tendency terms [see Lupo et al. (1992) for details], 


$$
\begin{aligned}
\underbrace{\frac{\partial \xi_{\mathrm{gs}}}{\partial t}=}_{\mathrm{A}} & \frac{1}{p_{s}-p_{t}}\left\{\int_{p_{t}}^{p_{s}}[\underbrace{-\mathbf{V} \cdot \nabla \xi_{a}}_{\mathrm{B}}+\underbrace{\mathbf{k} \cdot \boldsymbol{\nabla} \times \mathbf{F}}_{\mathrm{C}}-\underbrace{\frac{\partial \xi_{\mathrm{ag}}}{\partial t}}_{\mathrm{D}}-\underbrace{\omega \frac{\partial \xi_{a}}{\partial p}}_{\mathrm{E}}+\underbrace{\mathbf{k} \cdot\left(\frac{\partial \mathbf{V}}{\partial p} \times \boldsymbol{\nabla} \omega\right)}_{\mathrm{F}}+\underbrace{\xi_{a} \frac{\partial \omega}{\partial p}}_{\mathrm{G}}] d p\right\} \\
& -\frac{1}{p_{s}-p_{t}}\left[\frac{R}{f} \int_{p_{t}}^{p_{s}} \int_{p}^{p_{s}} \nabla^{2}(\underbrace{-\mathbf{V} \cdot \boldsymbol{\nabla} T}_{\mathrm{H}}+\underbrace{\frac{\dot{Q}_{\mathrm{LH}}}{c_{p}}}_{\mathrm{I}}+\underbrace{\frac{\dot{Q}_{\mathrm{SH}}}{c_{p}}}_{\mathrm{J}}+\underbrace{S \omega}_{\mathrm{K}} \frac{d p}{p} d p],\right.
\end{aligned}
$$

where all symbols have their usual meteorological meaning (e.g., Parsons and Smith 2004). Equation (1) implies that the near-surface changes in GV (term A) consist of the contributions due to vertically integrated absolute vorticity advection (term B), curl of the friction (term C), ageostrophic vorticity tendency (term D), vertical advection of absolute vorticity (term E), vorticity tilting (term $\mathrm{F}$ ), divergence or stretching interacting with absolute vorticity (term G), Laplacian of temperature advection (term $\mathrm{H}$ ), latent heating (term I), sensible heating (term J), and adiabatic cooling/heating or adiabatic temperature changes (term K). The justification for using the complete $\mathrm{Z}-\mathrm{O}$ equation rather than its quasigeostrophic form is that the former more fully accounts for vorticity and thermal forcing, especially the effects of ageostrophic motions.

\section{b. Omega equation}

The omega equation, obtained by combining the equations of motion, energy, ideal gas, continuity, and hydrostatic balance approximation and neglecting the $\beta$ term [see Pagé et al. (2007) for a complete derivation], takes the following form:

$$
\begin{aligned}
\frac{R}{p} \nabla^{2} S \omega+f \frac{\partial}{\partial p}\left(\xi_{a} \frac{\partial \omega}{\partial p}\right)-f \frac{\partial}{\partial p}\left(\omega \frac{\partial \xi_{a}}{\partial p}\right)+f \frac{\partial}{\partial p}\left[\mathbf{k} \cdot\left(\frac{\partial \mathbf{V}}{\partial p} \times \nabla \omega\right)\right]= & -f \frac{\partial}{\partial p}\left(-\mathbf{V} \cdot \nabla \xi_{a}\right)-f \frac{\partial}{\partial p}(\mathbf{k} \cdot \nabla \times \mathbf{F}) \\
& +f \frac{\partial}{\partial p}\left(\frac{\partial \xi_{\mathrm{ag}}}{\partial t}\right)-\frac{R}{p} \nabla^{2}(-\mathbf{V} \cdot \nabla T) \\
& -\frac{R}{p} \nabla^{2}\left(\frac{\dot{Q}_{\mathrm{LH}}}{c_{p}}\right)-\frac{R}{p} \nabla^{2}\left(\frac{\dot{Q}_{\mathrm{SH}}}{c_{p}}\right)
\end{aligned}
$$

where all symbols have their usual meteorological meaning (e.g., Pagé et al. 2007).

\section{c. Combining the $\mathrm{Z}-\mathrm{O}$ and omega equations}

We use a partitioning technique similar to Räisänen (1997) to combine the $\mathrm{Z}-\mathrm{O}$ and omega equations. First, we calculate the contribution of the six righthand-side (rhs) terms in Eq. (2) separately by means of homogeneous boundary conditions. The numerical procedure is explained in the next section. Then, by using Eq. (1), we obtain six components of the Z-O equation,

$$
\begin{aligned}
\frac{\partial \xi_{\mathrm{gs}}}{\partial t}= & \left(\frac{\partial \xi_{\mathrm{gs}}}{\partial t}\right)_{\mathrm{VA}}+\left(\frac{\partial \xi_{\mathrm{gs}}}{\partial t}\right)_{\mathrm{TA}}+\left(\frac{\partial \xi_{\mathrm{gs}}}{\partial t}\right)_{\mathrm{LH}} \\
& +\left(\frac{\partial \xi_{\mathrm{gs}}}{\partial t}\right)_{\mathrm{AG}}+\left(\frac{\partial \xi_{\mathrm{gs}}}{\partial t}\right)_{\mathrm{FR}}+\left(\frac{\partial \xi_{\mathrm{gs}}}{\partial t}\right)_{\mathrm{SH}}
\end{aligned}
$$

where the six components on the rhs are the total contribution of the vorticity advection (VA), temperature advection (TA), latent heat release (LH), ageostrophic vorticity tendency (AG), friction (FR), and sensible heating (SH) terms to the near-surface GV tendency. For example, the vorticity advection component [first term on the rhs of Eq. (3)] is calculated as

$$
\begin{aligned}
\left(\frac{\partial \xi_{\mathrm{gs}}}{\partial t}\right)_{\mathrm{VA}}= & \frac{1}{p_{s}-p_{t}} \int_{p_{t}}^{p_{s}}\left[-\mathbf{V} \cdot \nabla \xi_{a}-\omega_{\mathrm{VA}} \frac{\partial \xi_{a}}{\partial p}+\mathbf{k} \cdot\left(\frac{\partial \mathbf{V}}{\partial p} \times \nabla \omega_{\mathrm{VA}}\right)+\xi_{a} \frac{\partial \omega_{\mathrm{VA}}}{\partial p}\right] d p \\
& -\frac{1}{p_{s}-p_{t}} \frac{R}{f} \int_{p_{t}}^{p_{s}} \int_{p}^{p_{s}} \nabla^{2}\left(S \omega_{\mathrm{VA}}\right) \frac{d p}{p} d p
\end{aligned}
$$


where $\omega_{\mathrm{VA}}$, calculated as

$$
\frac{R}{p} \nabla^{2} S \omega_{\mathrm{VA}}+f \frac{\partial}{\partial p}\left(\xi_{a} \frac{\partial \omega_{\mathrm{VA}}}{\partial p}\right)-f \frac{\partial}{\partial p}\left(\omega_{\mathrm{VA}} \frac{\partial \xi_{a}}{\partial p}\right)+f \frac{\partial}{\partial p}\left[\mathbf{k} \cdot\left(\frac{\partial \mathbf{V}}{\partial p} \times \nabla \omega_{\mathrm{VA}}\right)\right]=-f \frac{\partial}{\partial p}\left(-\mathbf{V} \cdot \nabla \xi_{a}\right),
$$

corresponds to the part of the vertical velocity that is due to the vorticity advection term. The total contribution by the vorticity advection component is composed of a direct effect, given by the first rhs term in Eq. (4), and a set of indirect effects, given by the remaining terms. These indirect effects are influenced by the role of horizontal vorticity advection in forcing vertical motion, as given in Eq. (5). In other words, because the horizontal vorticity advection changes the vertical circulation, it may affect the surface convergence-divergence through the vertical advection, tilting, stretching, and adiabatic coolingwarming terms [E, F, G, and K in Eq. (1)]. However, the adiabatic warming-cooling will have the strongest indirect effect on synoptic-scale weather systems such as ETCs [e.g., see Tables $3 a$ and $3 b$ in Parsons and Smith (2004)]. Similar expressions can be derived for the other components (see auxiliary text in supplemental material).

\section{Data and numerical computation}

a. Data

The data used in this study are from the Modern-Era Retrospective Analysis for Research and Application (MERRA). A description of the MERRA system is given by Cullather and Bosilovich (2011) and Rienecker et al. (2011). MERRA is a National Aeronautics and Space Administration (NASA) reanalysis for the satellite era (1979-present) using the Goddard Earth Observing System Atmospheric Data Assimilation System, version 5 (GEOS-5). It was undertaken by NASA's Global Modeling and Assimilation Office with the objectives of placing the observations from NASA's Earth Observing System satellites in a climate context and improving on the hydrologic cycle represented in earlier generations of reanalyses. We used instantaneous analysis fields (geopotential height, temperature, $u$ and $v$ wind components, vertical motion, and sea level pressure), which are available every $3 \mathrm{~h}$ on a three-dimensional grid with a horizontal resolution of $1.25^{\circ} \times 1.25^{\circ}$ and 19 pressure levels with $50-\mathrm{hPa}$ vertical increments from 1000 to $100 \mathrm{hPa}$. The atmospheric surface data are hourly time-averaged sensible heat flux and total surface precipitation flux on a $0.5^{\circ} \times 0.66^{\circ}$ spatial resolution.

\section{b. Trajectories and cyclone events}

This study concerns the development of long-lived, intense, and large-scale extratropical low pressure systems over the North Atlantic during the winter months. An algorithm for feature tracking developed by Hodges (1999) was used to construct storm tracks from the 6-hourly MERRA data from 1979 to 2009. The relative vorticity field $\xi$ at $850 \mathrm{hPa}$ was then used to detect the low pressure centers [see Sorteberg and Walsh (2008) for details]. Genesis is defined as the first time that the $\xi$ exceeds $0.5 \times 10^{-4} \mathrm{~s}^{-1}$. Long-lived cyclones are then selected as those events where the relative vorticity remains larger than the threshold for at least 3 days after the genesis. To pick only intense low pressures, we calculated the total mean intensity, which is defined as the mean value for the relative vorticity at the cyclone center for all trajectories from 1979 to 2009 $\left(\sim 2 \times 10^{-4} \mathrm{~s}^{-1}\right)$, and then excluded those events with mean intensities that were less than the total mean intensity. Finally, cyclone trajectories crossing $40^{\circ} \mathrm{W}$ from west to east with their peak intensity occurring in December, January, or February were selected. By applying these thresholds, 100 cyclone events were finally available for making the composites. The trajectories for selected events are displayed in Fig. 1.

\section{c. Numerical implementation}

The GEOS-5 data assimilation system used to produce MERRA does not (or did not, at the time of production) extrapolate data to pressure levels greater than the surface pressure and, as such, these grid points are marked by undefined values. To fill the data below the ground, winds were set to zero and temperatures were calculated assuming a lapse rate of $6.5^{\circ} \mathrm{C} \mathrm{km}^{-1}$. Geopotential heights were then determined from the hypsometric relationship and interpolated temperatures. We need the below-ground data to avoid discontinuities when calculating the gradient and Laplacian of the data. The surface data were also interpolated spatially using a nearest-neighbor interpolation method to the same grid as that of the three-dimensional data, while a linear interpolation was utilized to determine the surface data every $3 \mathrm{~h}$. Using a polar stereographic projection true at the cyclone center, defined as grid point with the maximum $950-\mathrm{hPa} \mathrm{GV}$, all data are first projected onto a surface of $2000 \mathrm{~km}$ in length and width. The horizontal resolution is chosen to be approximately $138 \mathrm{~km}$ in the $x-y$ direction corresponding to the distance between two adjacent grid points of the same longitude in the MERRA data. The calculations are performed on the 


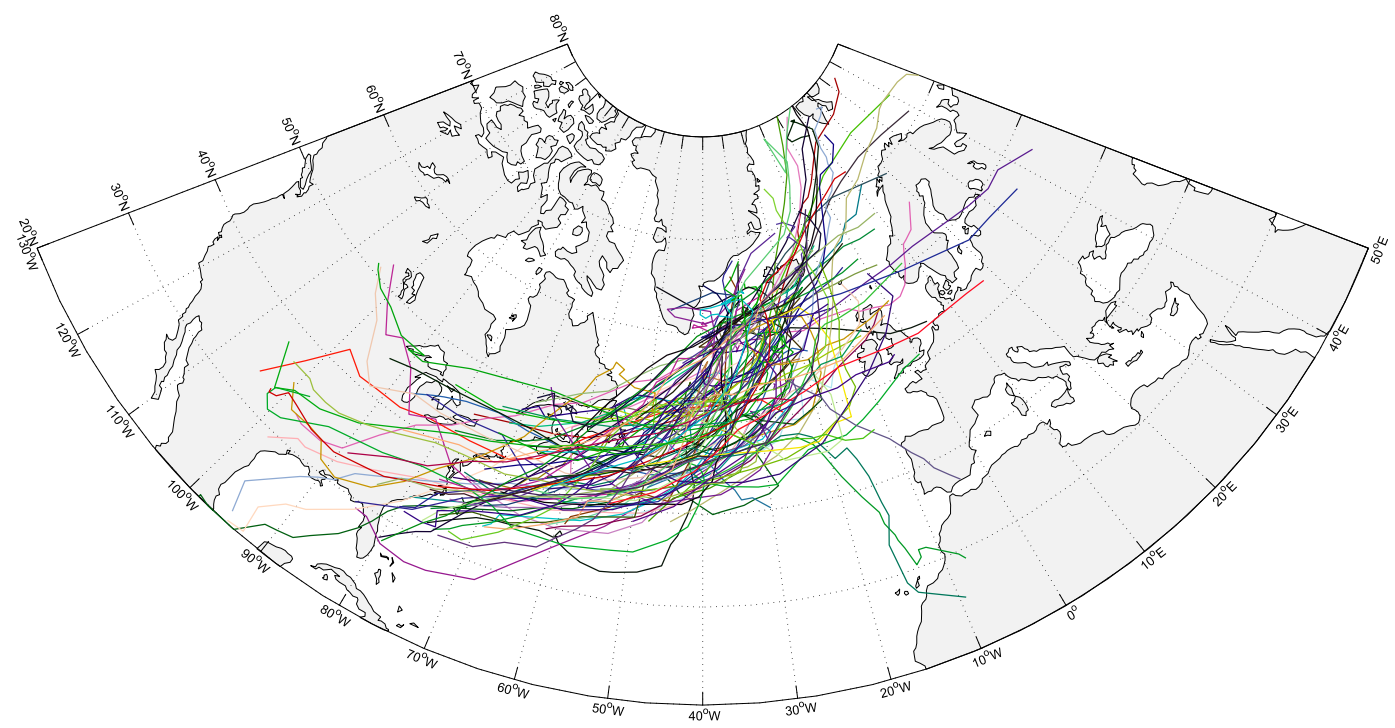

FIG. 1. Trajectories of the 100 most intense North Atlantic wintertime (December-February) cyclones (1979-2009) used for compositing.

projected surface, and then all calculated values are converted back to the sphere.

The grid-scale latent and sensible heating can be parameterized employing a methodology (Caron et al. 2007) that uses the total surface precipitation flux and positive diabatic residuals estimated by the thermodynamic equation in all pressure levels in the troposphere (pressure levels below $300 \mathrm{hPa}$ ). The diabatic residual was calculated using the following form of the thermodynamic energy equation (Holton 2004):

$$
\frac{\partial T}{\partial t}+\mathbf{V} \cdot \nabla T-S \omega=\frac{\dot{Q}}{c_{p}},
$$

where the first derivative of the temperature is the Eulerian temperature tendency. The diabatic processes are assumed here to be only latent heat release in the troposphere (below $300 \mathrm{hPa}$ ) and sensible heating in the boundary layer (below $850 \mathrm{hPa}$ ).

The omega equation [Eq. (2)] was solved iteratively using a three-dimensional successive underrelaxation method (Haltiner and Williams 1980) to estimate the vertical velocities for all pressure levels over the ground, while it was set to zero for the pressure levels larger than the surface pressure. To solve Eq. (2), suitable boundary conditions must be specified before the successive relaxation method is used. The lateral, upper $(70 \mathrm{hPa})$, and initial values of omega are set to zero. The bottom boundary at each grid point is the isobaric level (to the nearest $50 \mathrm{hPa}$ ) just under the model's surface pressure. The successive relaxation method can only be used if Eq. (2) is elliptic. Following the procedure explained by
Pauley and Nieman (1992), $S$ and $(\xi+f)$ are slightly adjusted and then smoothed by applying a fourth-order, two-dimensional Shapiro filtering scheme (Shapiro 1970) to eliminate any discontinuities where the ellipticity criteria were applied. The ageostrophic vorticity tendency is calculated as a residual of the relative and $\mathrm{GV}$ tendency. Finally, the friction term is parameterized using the balanced flow equation in the boundary layer (e.g., Azad and Sorteberg 2009).

The lowest pressure boundary $p_{s}$ in the $\mathrm{Z}-\mathrm{O}$ equation is defined as the first pressure level above the surface to reflect surface development and also to include nearsurface processes. The nearest pressure level to the ground, considering the computational frame for the cyclone domain and the pressure levels used for this study, was chosen to be $950 \mathrm{hPa}$. The upper level $p_{t}$ was defined as $100 \mathrm{hPa}$ to include upper-tropospheric and lower-stratospheric processes. Horizontal and vertical derivatives were calculated using a second-order finitedifference method, while the trapezoidal rule was used to estimate the vertical integrals. A second-order, central first derivative was used to calculate the Eulerian temperature tendency.

All GV tendencies were filtered using a fourth-order, two-dimensional Shapiro filter to remove small-scale noise primarily due to the Laplacian operators in the $\mathrm{Z}-\mathrm{O}$ equation. However, because of the limited horizontal computational domain, the effect of boundaries cannot be ignored. Therefore, the filtering scheme was applied only a few times ( $\sim 10$ times) to gain the best spatial and temporal correlation between the reanalysis and total calculated tendencies. The Shapiro filter 
applied to the GV tendency fields with grid distances of about $138 \mathrm{~km}$ retains essentially zero information at horizontal wavelengths less than about $300 \mathrm{~km}$, approximately $50 \%$ of the information around $400 \mathrm{~km}$, and over $99.9 \%$ of the information for wavelengths above $1000 \mathrm{~km}$. We did not observe any significant changes in the percentage of composite contribution by each forcing term to the 950-hPa GV tendencies at the cyclone center when filtering was applied between 10 and 50 times. However, the values of the total Z-O tendencies were sensitive to the number of filtering applications so that tendency values were $10 \%-20 \%$ larger when filtering was applied 50 times.

\section{d. Cyclone compositing}

The compositing methodology was previously utilized in studying tropical cyclone (e.g., Bengtsson et al. 2007) and ETC structure (e.g., Bengtsson et al. 2009; Catto et al. 2010; Hodges et al. 2011; Dacre et al. 2012). The first step is to determine the cyclone centers where the geostrophic relative vorticity at $950 \mathrm{hPa}$ is a maximum. The next step is to create a radial coordinate system centered on the North Pole with a $10^{\circ}$-radius spherical cap and to rotate it to lie over the cyclone center. The direction of propagation of the cyclone is determined using the displacement of the cyclone center during $6 \mathrm{~h}$ using a second-order, central firstderivative finite differencing. The next step is to rotate the preferred direction of the spherical cap to the direction of the propagation at this point [see Fig. 3 in Catto et al. (2010)]. The rotation of the analysis into a coordinate oriented along the cyclone movement reduces the smearing and instability (large case-to-case variability) problems that can plague such analyses. These processes are applied during the entire lifetime of the cyclone. Finally, the region of the spherical cap is extracted for averaging with the other selected cyclones. For example, for 10 cyclones each lasting $72 \mathrm{~h}$ (3 days for 6-hourly data), we have $120(10 \times 72 / 6)$ spherical caps for averaging. We make no attempt to account for the cyclone size for two reasons: first, because the main aim here is to analyze the contributions at the cyclone center and, second, because the storms in vorticity appear smaller, making the $10^{\circ}$ spherical cap radius $(\sim 1000 \mathrm{~km})$ adequate to capture the intense cyclone structure.

Additionally, we divide the life cycle of each cyclone in two parts corresponding to the periods of development and decay. To do this, we first find the point along each track where the maximum geostrophic relative vorticity at $950 \mathrm{hPa}$ is reached. We define the time of this point $t_{c}$ as the time of the peak intensity for that case. Then the period before (after) the time of the peak intensity is defined as the development (decay) phase. Moreover, we consider only positive (negative) GV tendencies to make composites during the development (decay) phase. As such, we do not take into account any short periods of dissipation (intensification) in the development (decay) stage. We retain the $950-\mathrm{hPa}$ tendency values at the cyclone center for all times during the development phase. To analyze the mean tendencies and their variability, this process is repeated for all cyclone events. Therefore, there are two types of variances when we make composites of tendency values: 1) case-to-case and 2) timeto-time variability. The former is the difference in tendencies between each cyclone at each time of interest (e.g., 1 day before the peak intensity). The latter is the variability within each cyclone at different times. The variable composite life cycles have different cyclone populations at different times. We therefore construct constant-population composites to give a sense of how the temporal evolution of such composites differs from the temporal evolution of variable composites. The constant-population composites consist of three subsets. These subsets include the evolution of quantities for all cyclones that develop at least 1 (DAY1), 2 (DAY2), and 3 or more (DAY3) days before the peak intensity. The number of cyclones in DAY1, DAY2, and DAY3 is 10,47 , and 43, respectively. This paper includes the validation of the composite-cyclone life cycle and results from the analysis of the development phase. The diagnosis of the $\mathrm{Z}-\mathrm{O}$ forcing mechanisms acting to dissipate the composite cyclone during the decay phase is presented in Part II.

\section{Validation}

The reliability of the diagnostic calculations and parameterizations in Eq. (1) is examined. As a check for computational accuracy in the Z-O tendencies, the 950-hPa GV tendency of the reanalysis was calculated by first taking the Laplacian of the height geopotential at $950 \mathrm{hPa}$ and then using a 6-h central finite difference,

$$
\left(\frac{\partial \xi_{g}}{\partial t}\right)_{\text {reanalyses }}=\frac{\partial}{\partial t}\left(\frac{1}{f_{o}} \nabla^{2} \varphi\right) \quad \varphi=g h,
$$

where $h$ and $\varphi$ are, respectively, the height and geopotential height at $950 \mathrm{hPa}$. We provide Fig. 2 to demonstrate the range of values over which the $\mathrm{Z}-\mathrm{O}$ equation is capable of reproducing the reanalysis tendencies. The one-to-one line in Fig. 2 a shows that the $\mathrm{Z}-\mathrm{O}$ tendencies are generally larger than the reanalysis values. The equation for the linear regression, provided 

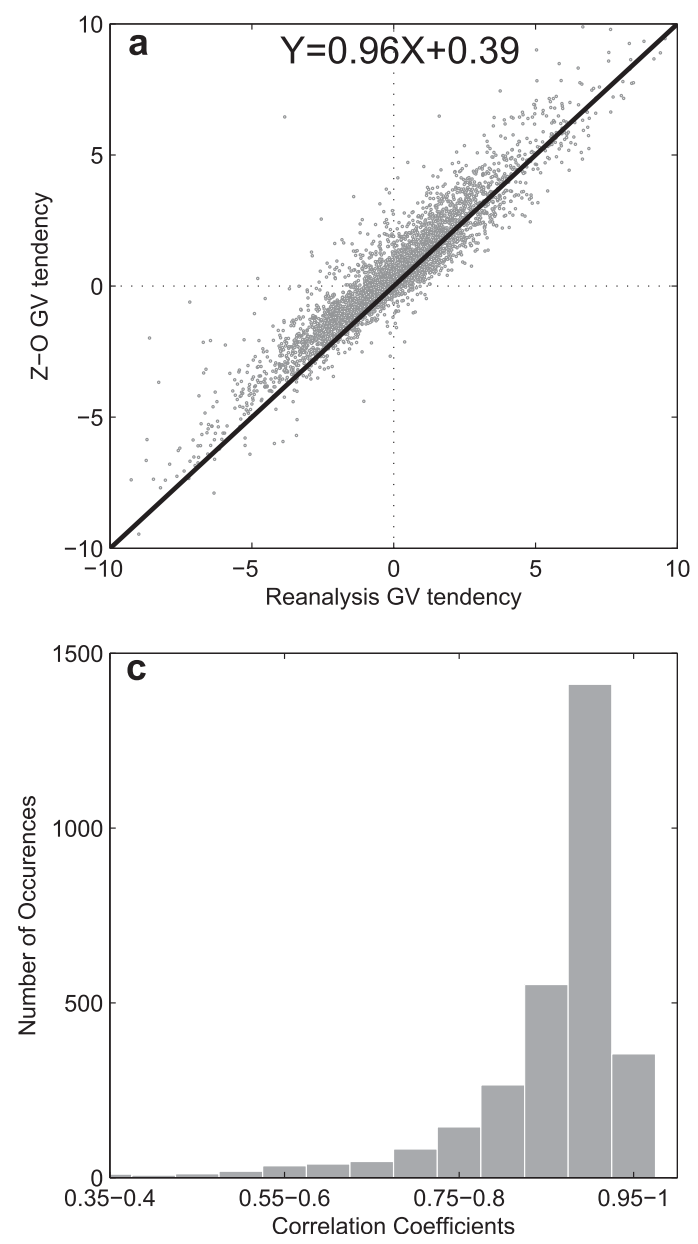

on the top of this figure, demonstrates the ability of the $\mathrm{Z}-\mathrm{O}$ equation to model the surface development at the cyclone center. In addition, the quantile-quantile plot in Fig. $2 b$ suggests that $\mathrm{Z}-\mathrm{O}$ and reanalysis tendencies come from the same distribution. The pattern correlation coefficients (CCs) between the reanalysis [Eq. (7)] and the $\mathrm{Z}-\mathrm{O}$ fields [Eq. (3)] for all events are shown in Fig. 2c. These indicate good agreement, with $80 \%$ of the cases having CCs above 0.7 and only $6 \%$ less than 0.5 . The average is 0.83 .

An issue related to the calculations in the tendency equation is the movement of the cyclone system. Following Sinclair and Revell (2000) in a quasi-Lagrangian framework with a cyclone moving with velocity $\mathbf{C}$ (here, the cyclone-center velocity), the Eulerian GV tendency can be written as

$$
\frac{\partial \xi_{\mathrm{gs}}}{\partial t}=\frac{\delta \xi_{\mathrm{gs}}}{\delta t}-\mathbf{C} \cdot \nabla \xi_{\mathrm{gs}},
$$

where the first term on the rhs is the change following the storm (storm-related) and the second term is the

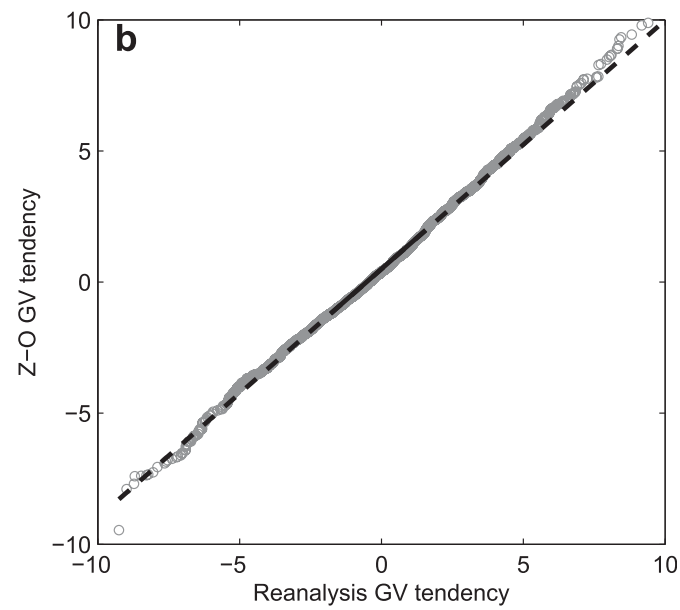

FIG. 2. (a) The Z-O vs reanalysis $950-\mathrm{hPa}$ GV tendencies $\left(10^{-9} \mathrm{~s}^{-2}\right)$ at the cyclone center. The black solid line is for the 1:1 comparison. The equation for the linear regression between $\mathrm{Z}-\mathrm{O}$ and reanalysis $\mathrm{GV}$ tendencies is provided. (b) The quantile-quantile (q-q) plot of 950-hPa Z-O and reanalysis 950-hPa GV tendencies $\left(10^{-9} \mathrm{~s}^{-2}\right)$ at the cyclone center. Superimposed is a solid black line joining the first and third quartiles and a dashed line, which is extrapolated out to the ends of the sample to help evaluate the linearity of the data. (c) Distribution of pattern correlation coefficients between $\mathrm{Z}-\mathrm{O}$ and reanalysis $950-\mathrm{hPa} \mathrm{GV}$ tendencies in the cyclone area.

system advection. This equation is used to isolate the storm-related and system advection part in the reanalysis and $\mathrm{Z}-\mathrm{O}$ tendencies. The same equation could, in principle, be used for each forcing term in the $\mathrm{Z}-\mathrm{O}$ equation. However, the GV induced by individual Z-O forcing terms cannot be directly calculated. Lupo et al. (1992) suggest that, since the center of the system is a point at which the system advection part is zero, the grid point with maximum $950-\mathrm{hPa} \mathrm{GV}$ can be used to apply a nine-point-averaged smoothing scheme to all grid points in the cyclone area in order to remove the system advection part of the tendencies. The nine grid points are represented by the center of the cyclone and the eight grid points that surround the center point.

The 950-hPa reanalysis and $\mathrm{Z}-\mathrm{O}$ GV tendencies are displayed in Fig. 3 for the development phase of the composite cyclone life cycle on a $10^{\circ}$-geodesic-radius region $(\sim 1100 \mathrm{~km})$. The system advection part is almost zero at the cyclone center, yielding a very small difference between the Eulerian and storm-related tendencies 
(a)

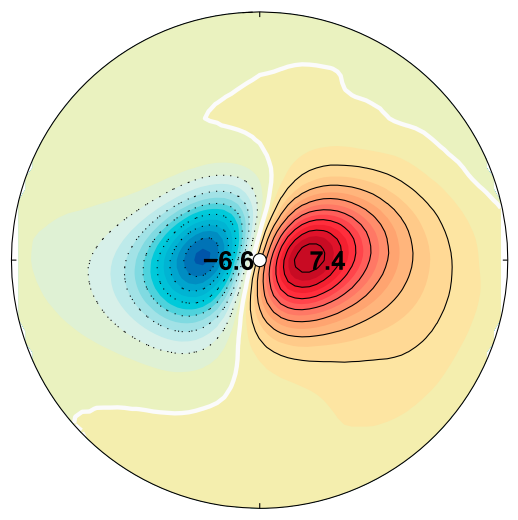

(d)

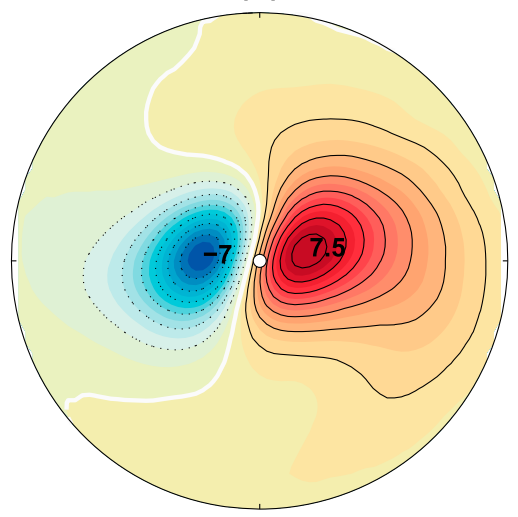

(b)

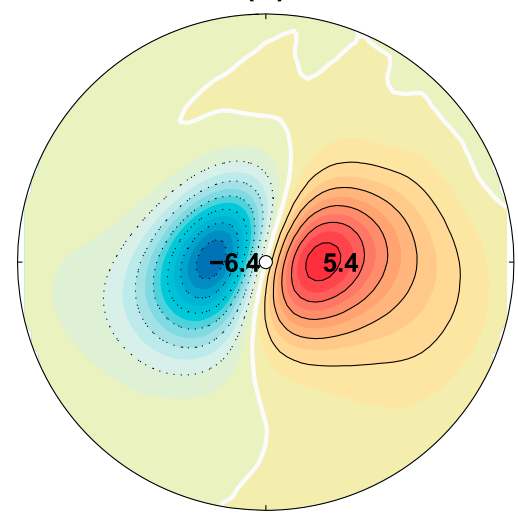

(e)

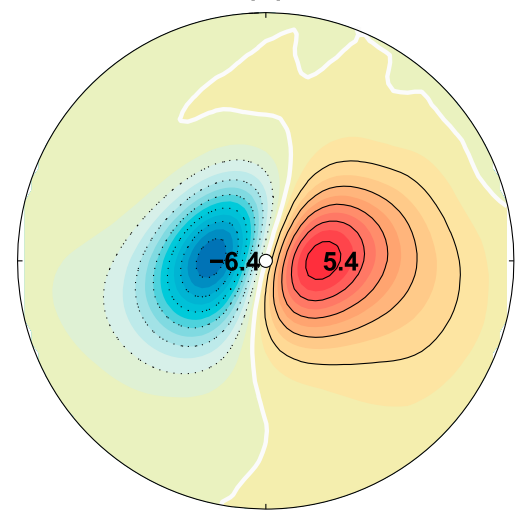

(c)

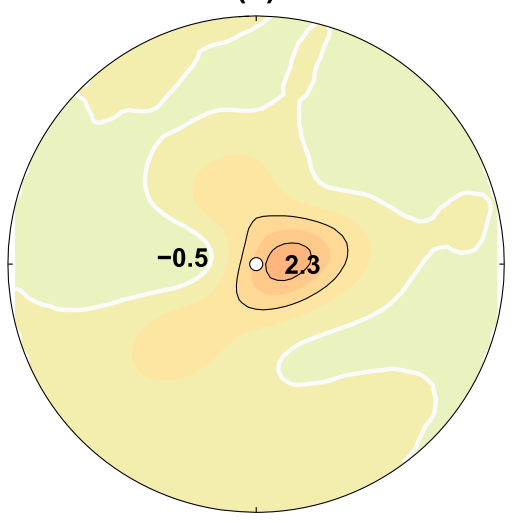

(f)

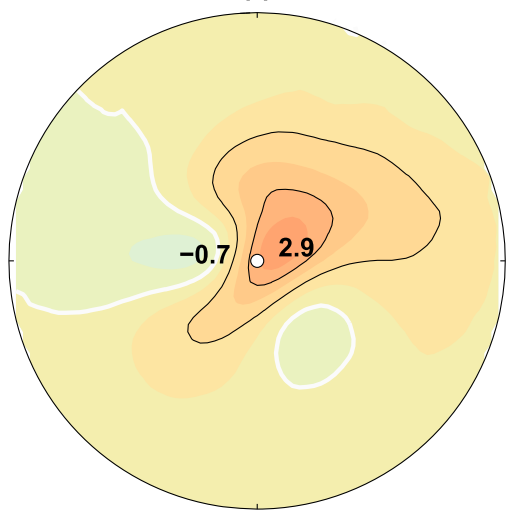

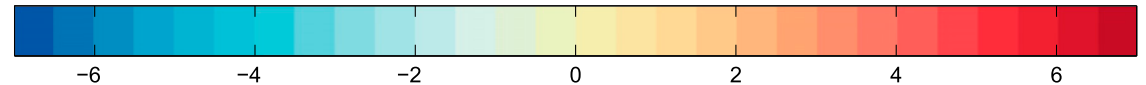

FIG. 3. Composites of (a)-(c) the reanalysis and (d)-(f) Z-O 950-hPa GV tendency $\left(10^{-9} \mathrm{~s}^{-2}\right)$ averaged for the entire development phase. Fields are (a),(d) the 950-hPa GV tendencies; (b),(e) its system advection part; and (c),(f) its storm-related part on a $10^{\circ}$-radius region. The white circle and line show the cyclone center and the zero tendencies, respectively. The direction of the movement of the composite cyclone is to the right.

at this grid point. However, most $(\sim 70 \%)$ of the $\mathrm{GV}$ tendency in reanalysis and the $\mathrm{Z}-\mathrm{O}$ equation are associated with the system advection part (Figs. 3b,e). When the advection part is removed, the composite cyclone center is consistently in the area of positive tendencies for both the reanalysis and $\mathrm{Z}-\mathrm{O} \mathrm{GV}$ tendencies (Figs. 3c,f).

\section{Composite results}

a. Evolution of 950-hPa GV, sea level pressure, and precipitation rate

Figure 4 shows the time evolution of $950-\mathrm{hPa} \mathrm{GV}$, sea level pressure (SLP), and precipitation rate at the cyclone center for the period of 3 days $(72 \mathrm{~h}$ ) before the peak intensity. We use the 25 th- 75 th quantiles to examine the variability in the tendencies. Variability is largest at the end of development for the $950-\mathrm{hPa}$ GV and SLP. The extents of the variability boxes reveal the large spreads of the dynamics in the composite cyclones. On average, the length of the quantiles boxes is less than $10 \mathrm{hPa}$ for SLP and $1 \times 10^{-4} \mathrm{~s}^{-1}$ for 950 $\mathrm{hPa}$ GV (Figs. $4 \mathrm{a}-\mathrm{c}$ ). Mean and median values are almost equal, which implies that the mean value is a reliable measure for assessing composite contributions to the selected cyclones. The evolution of SLP and $950 \mathrm{hPa} \mathrm{GV}$ are similar in the sense that the most intense SLP declines correspond to the largest increases in the $950-\mathrm{hPa} \mathrm{GV}$, thus confirming the latter as a convenient quantity for analyzing the development of surface cyclone dynamics. The range of variability is significant for the precipitation rate $\left(\sim 2 \times 10^{-4} \mathrm{~kg} \mathrm{~m}^{-2} \mathrm{~s}^{-1}\right)$ during the entire development 

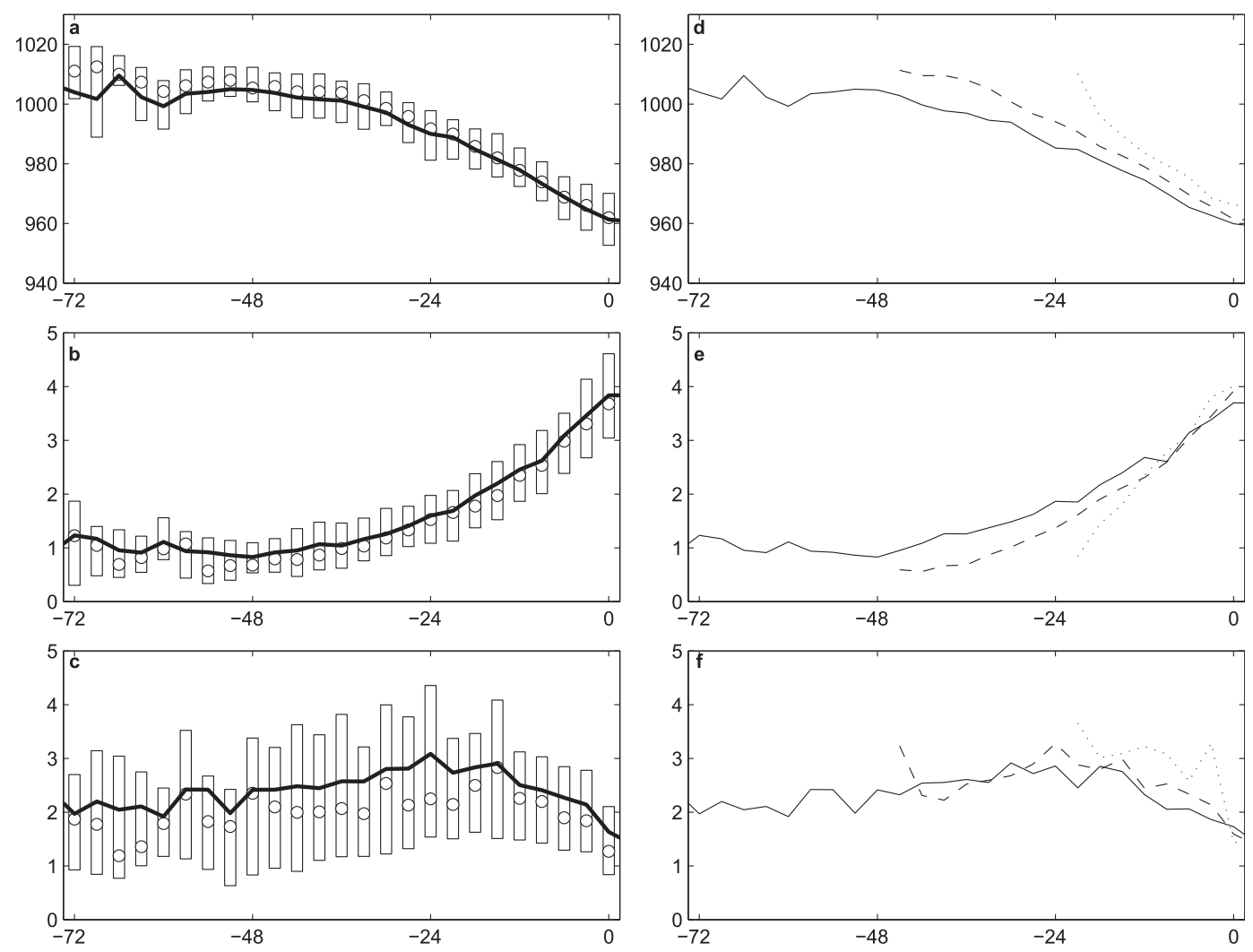

FIG. 4. (left) Evolution of the composite (a) sea level pressure (hPa), (b) $950-\mathrm{hPa} G \mathrm{GV}\left(10^{-4} \mathrm{~s}^{-1}\right)$, and (c) precipitation rate $\left(10^{-4} \mathrm{~kg} \mathrm{~m}^{-2} \mathrm{~s}^{-1}\right)$ at the cyclone center for the period of 3 days $(72 \mathrm{~h})$ before peak intensity (see text). Boxes are the 25th-75th percentiles, circles are the median, and the solid thick line is the mean. (right) The life cycle of subcomposite (d) sea level pressure, (e) 950-hPa GV, and (f) precipitation rate for cyclones that develop at least 1 (dotted), 2 (dashed), and 3 or more days (solid) before the peak intensity.

phase. This is also evident in the differences between the mean and median values. Such a case dependency is also seen when we examine the precipitation rate inside a $10^{\circ}$-radius region from the cyclone center (not shown).

The constant-population subcomposites (Figs. 4d-f) feature the evolution of cyclones with different development periods. While all cyclones that exist for at least 1 day (DAY1) before the peak intensity experience the explosive generation and evolution, most of the cyclones that exist for 2 or more days (DAY2 and DAY3) before the peak intensity show first a weak deepening after the genesis and then a strong intensification. All the cyclones in DAY1 exhibit latitudinally adjusted (e.g., Yoshida and Asuma 2004) central SLP falls greater than the $24 \mathrm{hPa}(24 \mathrm{~h})^{-1}$, characteristic of "bombs," as defined by Sanders and Gyakum (1980). A common evolution characteristic in all subsets is the reduction in the precipitation rate at the end of the development [see Fig. 4 in Bengtsson et al. (2009)]. At this period, as the occlusion of the front occurs, the forcing mechanisms responsible for lifting of the air are collapsing.

\section{b. Evolution of reanalysis and $\mathrm{Z}-\mathrm{O}$ tendencies}

Recall that we focus on the nine-point-averaged 950-hPa GV tendencies at the cyclone center. The reason for using the cyclone-center quantities is that the changes of the 950-hPa GV tendencies at this grid point are directly associated with the weakening or strengthening of the cyclonic circulation of the low pressure system. This is because the system advection is almost zero at this grid point (see also Figs. $3 \mathrm{~b}$ and $3 \mathrm{e}$ ). Figure 5 portrays the reanalysis and estimated $\mathrm{Z}-\mathrm{O}$ 950-hPa GV tendencies at the cyclone center for the same period in Fig. 4. In both composite time series, the largest increase in $950-\mathrm{hPa}$ GV occurs in a time period within -12 to $-6 \mathrm{~h}$. We refer to this period as the mature stage and the period before that as the incipient stage. The time histories of subcomposites (Figs. 5c,d) reveal that the DAY1 cyclones develop explosively and take higher values of 950-hPa 

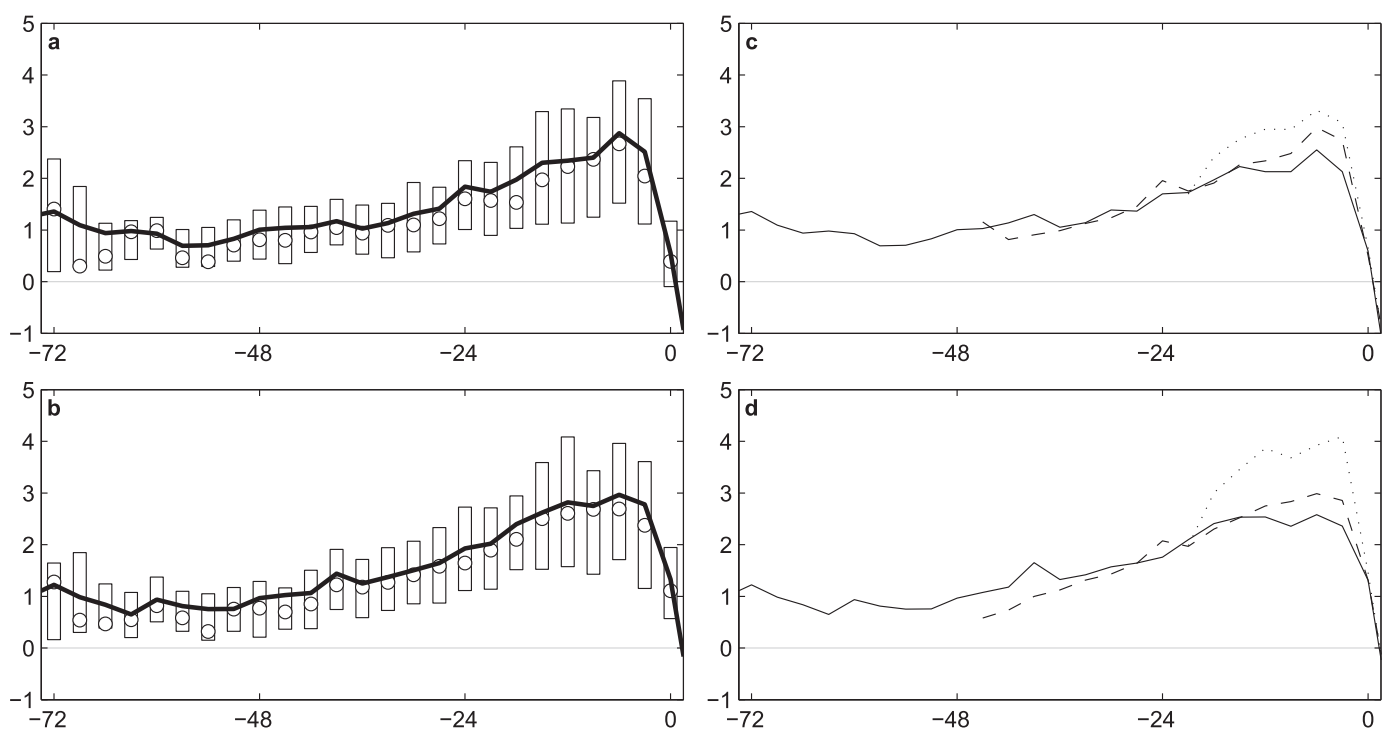

FIG. 5. As in Fig. 4, but for the composite (a),(c) 950-hPa Z-O and (b),(d) reanalysis GV tendencies $\left(10^{-9} \mathrm{~s}^{-2}\right)$.

GV tendency compared to the DAY2 and DAY3 cyclones. This explains the higher variability $(\sim 2 \times$ $10^{-9} \mathrm{~s}^{-2}$ ) seen at the time of the maximum tendency in Figs. 5a and 5b. On the other hand, the DAY2 and
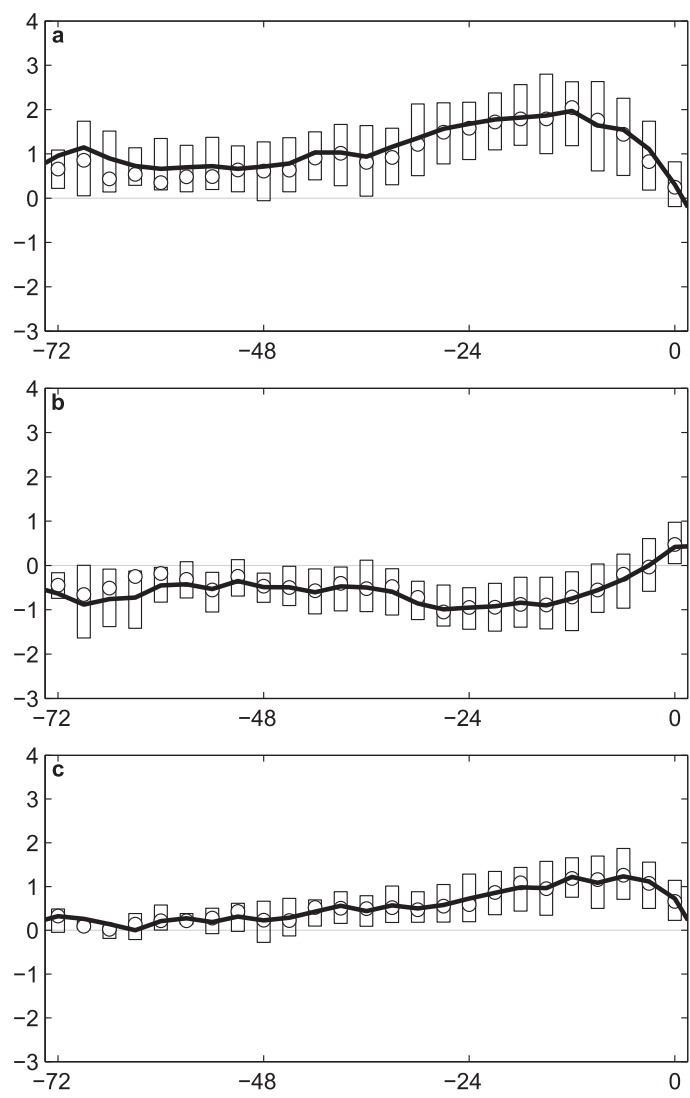

DAY3 cyclones have nearly equal tendency values during the mature stage. It is also apparent that the $\mathrm{Z}-\mathrm{O}$ tendencies are more overestimated in the DAY1 subcomposite.
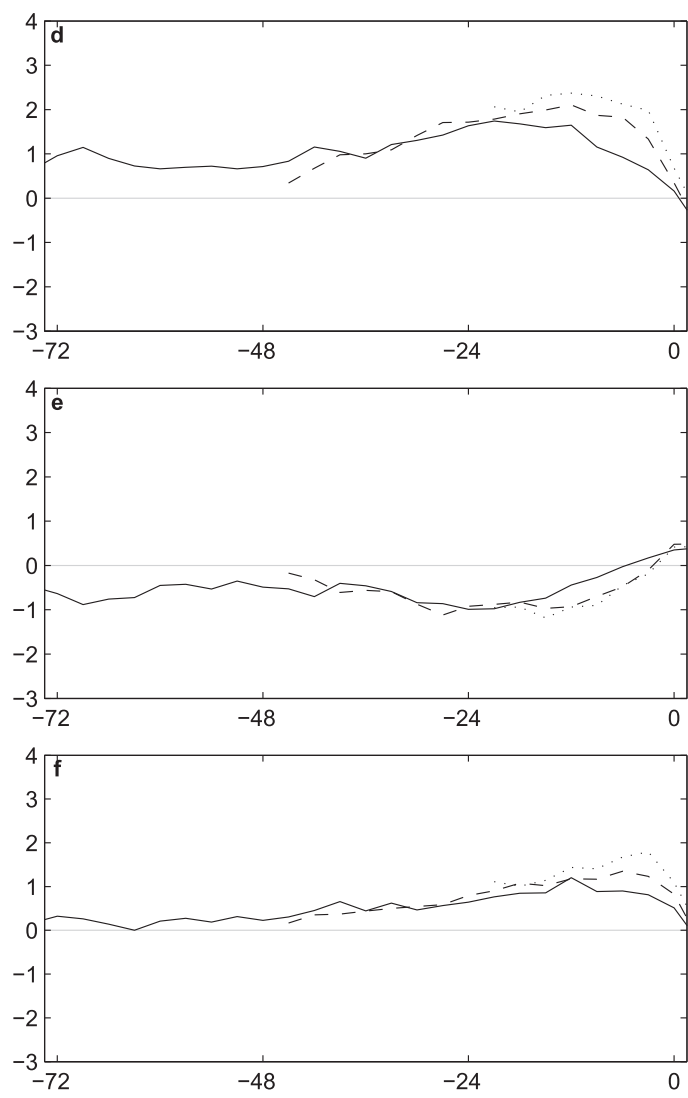

FIG. 6. As in Fig. 4, but for the (a),(d) direct; (b),(e) indirect; and (c),(f) total effect of the vorticity advection term on the $950-\mathrm{hPa} \mathrm{GV}$ tendencies $\left(10^{-9} \mathrm{~s}^{-2}\right)$. 

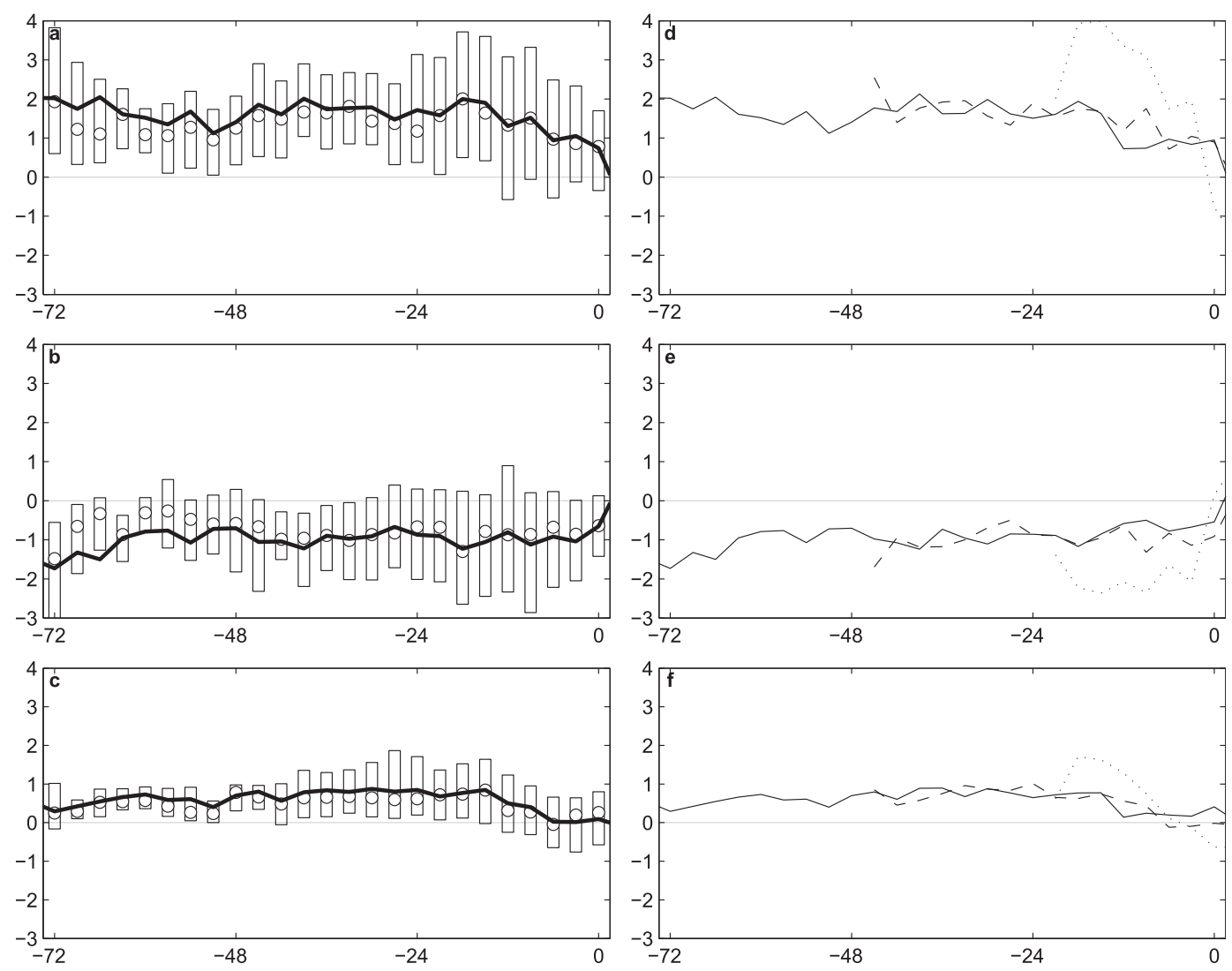

FIG. 7. As in Fig. 4, but for the (a),(d) direct; (b),(e) indirect; and (c),(f) total effect of the temperature advection term on the 950-hPa GV tendencies $\left(10^{-9} \mathrm{~s}^{-2}\right)$.

\section{c. Evolution of individual forcing terms}

We examine here the individual contributions by the $\mathrm{Z}-\mathrm{O}$ forcing terms to the formation and development of the cyclones. The direct effect of the vorticity advection term in generating 950-hPa CGV increases with time and is largest in the maturing cyclones (Figs. 6a,d). This effect is larger for explosively intensifying DAY1 cyclones, a result seen also in the composite analysis of land cyclones over the United States and southern Canada (Rolfson and Smith 1996). They show that the positive contribution by vorticity advection term in the $\mathrm{Z}-\mathrm{O}$ equation monotonically increases in magnitude for stronger development categories. The rapid reduction in the contribution at the end of development results from the rapid changes in the vertical tilt when the cyclone becomes barotropic (e.g., Bengtsson et al. 2009). The indirect effect (the influence of the forcing on the adiabatic term) of the vorticity advection term (Figs. 6b,e) is to oppose the development at all times, except at the end of the development. At $t_{c}$, the indirect effect becomes positive while the direct effect is nearly zero. Because the opposing influence of the indirect effect is reduced rather quickly over the mature cyclone center, the time of the maximum total effect is $-6 \mathrm{~h}$, around $6 \mathrm{~h}$ after the corresponding time for the direct effect.

In contrast to the vorticity advection term, the temperature advection contributes significantly to the strengthening of the cyclone in both the incipient and mature stages (Fig. 7a). At the end of the development, when the effect of the induced adiabatic cooling is still considerable (Fig. 7b), the total positive effect (Fig. 7c) diminishes with time. Comparing the evolution of subcomposites (Figs. 7d,e) during the last $24 \mathrm{~h}$, we see that the large variances $\left(\sim 3 \times 10^{-9} \mathrm{~s}^{-2}\right)$ in the composite contributions are mainly because of the larger forcing by the temperature advection term in the DAY1 cyclones. It is interesting that, for the DAY1 cyclones, the total effect becomes negative $6 \mathrm{~h}$ before the peak intensity. An example for such development is seen in the Experiment on Rapidly Intensifying Cyclones over the Atlantic (ERICA) intensive observing period 4 (IOP 4) cyclone of 4-5 January 1989 (Rausch and Smith 1996; Parsons and Smith 2004). For the DAY3 cyclones, the temperature advection continues to increase the 

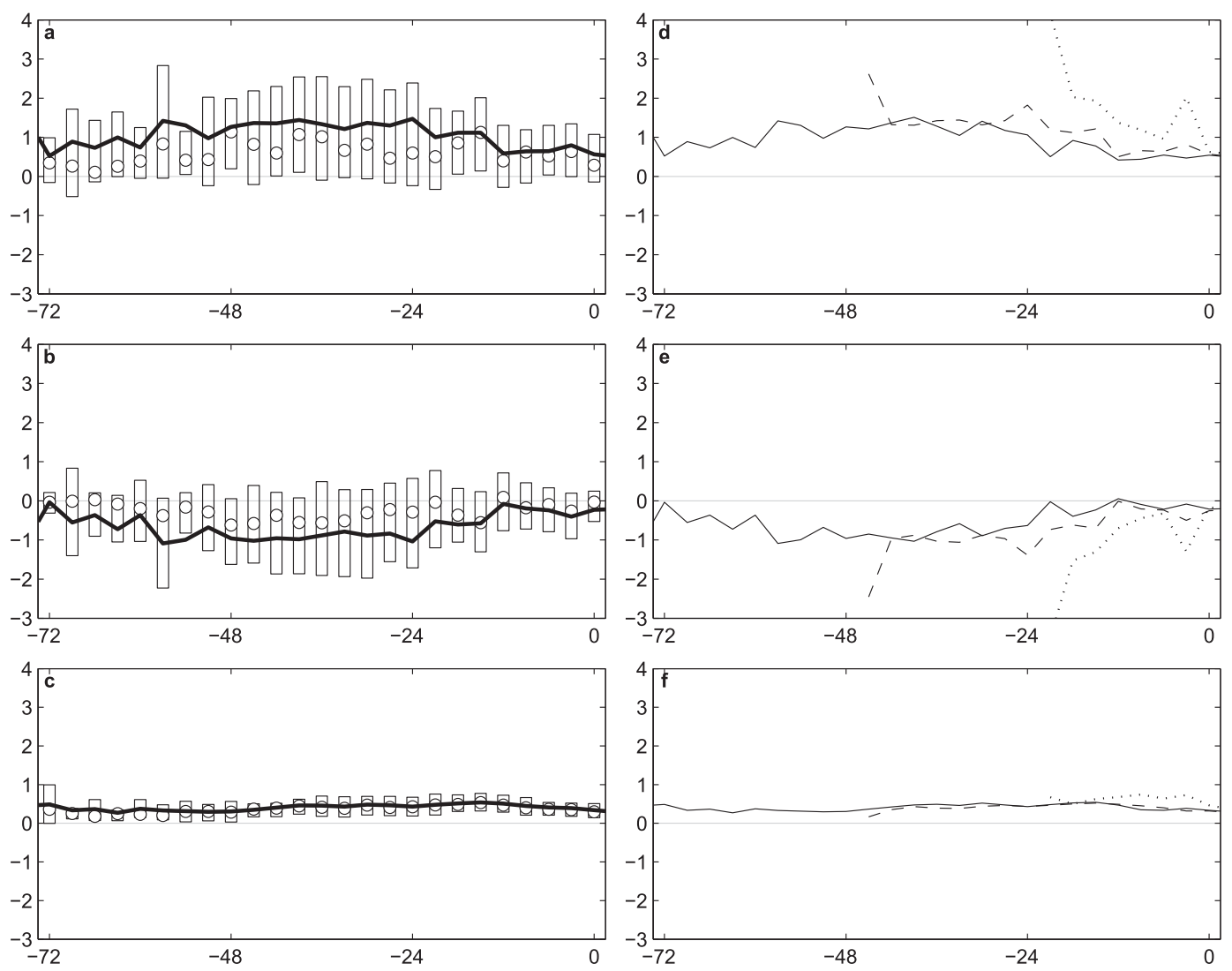

FIG. 8. As in Fig. 4, but for the (a),(d) direct; (b),(e) indirect; and (c),(f) total effect of the latent heating term on the 950-hPa GV tendencies $\left(10^{-9} \mathrm{~s}^{-2}\right)$.

950-hPa CGV; and for the DAY2 cyclones, its influence becomes negligible.

Contributions from the latent heating term are shown in Fig. 8. The direct and indirect effects are substantial (Figs. 8a,b), but there is also large variability in the contributions $\left(\sim 2 \times 10^{-9} \mathrm{~s}^{-2}\right)$ and distinctly different mean and median values (difference of about $0.5 \times$ $10^{-9} \mathrm{~s}^{-2}$ ). Apart from the truncation errors in the finite differencing and the parameterization technique that takes into account the estimated temperature tendency [see Eq. (6)], the broad spectrum of the precipitation rate seen in Fig. $4 \mathrm{c}$ suggests that the role of the latent heating term is strongly case dependent. Because all selected events develop over ocean, they are often flanked on their equatorward side by moist subtropical air. The range of variability in Fig. 8a implies that the latent heat released by the ascending moist air in some cases may be served, for example, to the increase in the translational speed of the surface low pressure (e.g., Davis et al. 1993) or to secondary cyclogenesis (e.g., Carrera et al. 1999). Further, the direct effect contains only the grid-scale latent heat release. Kuwano-Yoshida and Enomoto (2013) show that the weak latent heating due to unresolved subgrid-scale convection in their ensemble forecast model [the AGCM for the Earth Simulator (AFES) LETKF Experimental Re-Analysis (ALERA)] yields weak Z-O tendency and explosive cyclone forecast error over the Pacific Ocean. The total effect (Fig. 8c), however, shows smaller variabilities $\left(\sim 0.5 \times 10^{-9} \mathrm{~s}^{-2}\right)$ and smaller differences between median and mean tendencies. The inspection of subcomposites reveals that the largest forcing is seen for the DAY1 cyclones (Figs. 8d,e) and that the total effect in all subcomposites remains almost constant at most of the times (Fig. 8f).

The vertically integrated ageostrophic vorticity tendencies (Fig. 9) are nearly zero at the earlier periods of cyclone growth and take larger values in the mature stage. Interestingly, the direct and indirect effects support each other, yielding a remarkable total positive contribution. This total effect is greatest for the DAY1 cyclones, though it is also pronounced in DAY2 and DAY3 subsets. The effect of the ageostrophic vorticity tendency was ignored in most of the Z-O studies. Only in the recent work by Parsons and Smith (2004) was it recognized that this term could be significant. The 

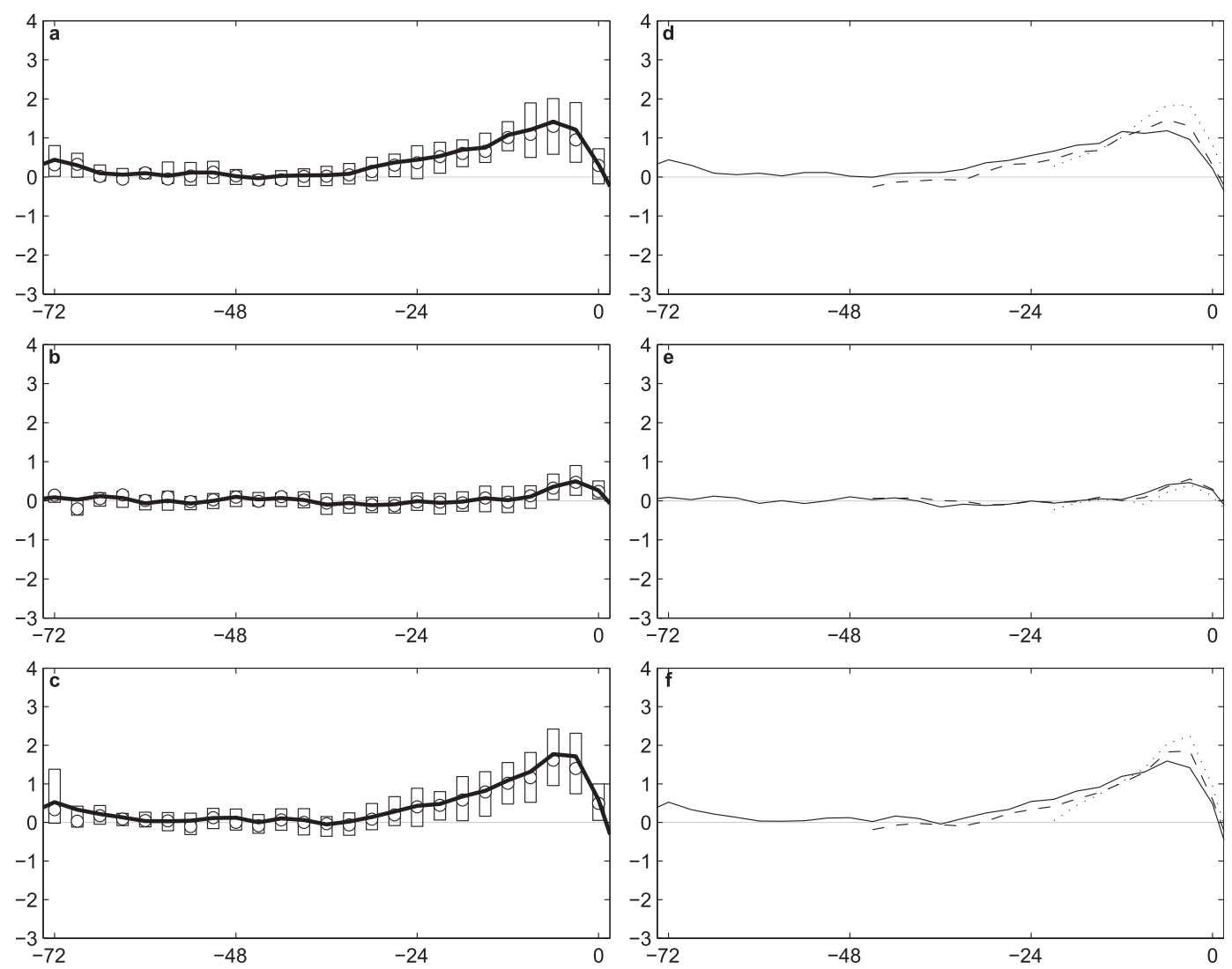

FIG. 9. As in Fig. 4, but for the composite 950-hPa GV tendencies $\left(10^{-9} \mathrm{~s}^{-2}\right)$ attributed to the (a),(d) direct; (b),(e) indirect; and (c),(f) total effect of the ageostrophic vorticity tendency term.

friction term (Fig. 10) always dissipates the 950-hPa CGV through both its direct and indirect effects. Because these two effects are negative, the total forcing by the friction term acts as the only prominent braking mechanism in slowing system intensification. Moreover, the strength of forcing in the DAY1 subcomposite (Fig. 10f) implies strong boundary layer interaction with the cyclone through Ekman pumping (e.g., Boutle et al. 2007). Lupo et al. (1992) show that the frictional forcing is largest at the end of explosive development. This is also evident in the evolution of the direct effect (Figs. 10a,d), but the largest total effect in our composites (Figs. 10c,f) occurs earlier, around -18 to $-12 \mathrm{~h}$ before $t_{c}$.

\section{d. Evolution of contribution profiles}

To show the role of individual Z-O forcing processes at different pressure levels, we construct vertical profiles of each forcing term over the cyclone center following Eqs. (17) and (18) in Rausch and Smith (1996). It should be mentioned that profiles of the thermal forcing terms (e.g., temperature advection) take into account the effects of both the Laplacian and double integrals in the
$\mathrm{Z}-\mathrm{O}$ equation [Eq. (1)], thus giving weight to the influences of the horizontal distribution (Smith 2000) and the vertical placement of heating or cooling (Rausch and Smith 1996). Here we show only the mean values of the profiles, as the median and mean fields are to a large extent similar to each other.

Figure 11 shows the composite time-pressure crosssectional profiles for the vorticity advection and temperature advection terms. The upper-cyclonic vorticity advection present for the entire development period contributes to the generation of $950-\mathrm{hPa}$ CGV by forcing divergence over the surface cyclone center (Fig. 11a). In all DAY1, DAY2, and DAY3 subsets, the strongest upper-level contribution occurs at around 250-350-hPa as the cyclone matures (not shown). This can be indicative of the approach and eventual superposition of an upper-tropospheric vorticity maximum over the surface low pressure (Lupo et al. 1992; Parsons and Smith 2004). The indirect effects are positive above $300 \mathrm{hPa}$, where air is descending as a result of vertically decreasing cyclonic vorticity advection. Below $400 \mathrm{hPa}$, indirect effects suppress deepening in the lower and middle troposphere via adiabatic cooling caused by 

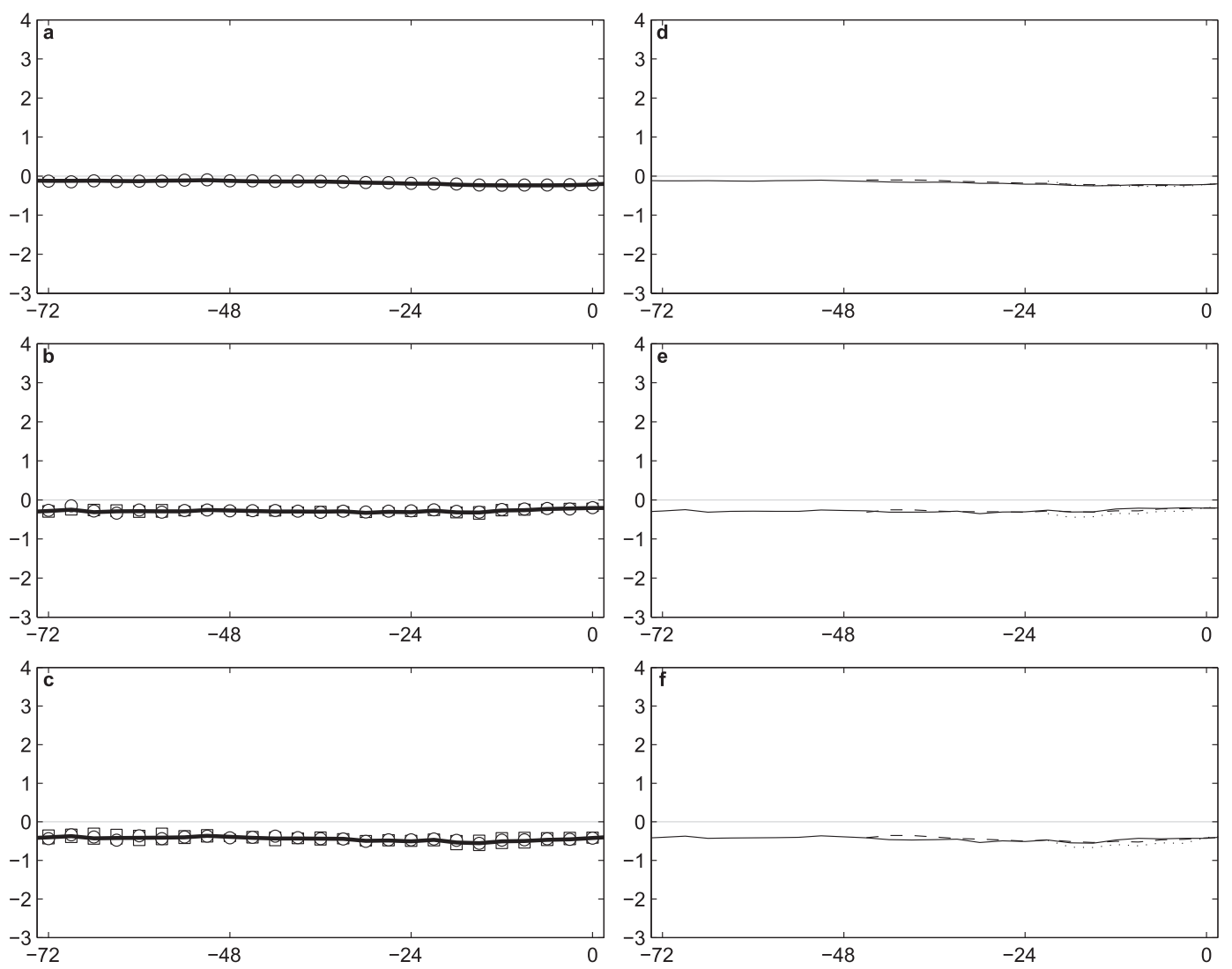

FIG. 10. As in Fig. 4, but for the (a),(d) direct; (b),(e) indirect; and (c),(f) total effect of the friction term on the 950-hPa GV tendencies $\left(10^{-9} \mathrm{~s}^{-2}\right)$.

induced upward vertical motion (Figs. 12a,b). At the end of development, a positive indirect effect is also present in the middle and lower troposphere. The examination of vertical motion fields over the cyclone center for the same period (not shown) reveals that this positive indirect effect is related to the cyclone center being removed from the cooling maximum (Smith 2000). The total influence of vorticity advection (Fig. 11c) is dominated by the positive direct (negative indirect) effect at upper levels (lower levels). Only in the last $6 \mathrm{~h}$ of development does the indirect effect dominate the forced tendencies over the cyclone center and generate 950-hPa CGV.

Warm-air advection is present at the upper and lower levels and contributes to cyclone growth (Fig. 11d). These strong effects are seen throughout the development phase in DAY1 and DAY2 subcomposites, while in the DAY3 cyclones (not shown), the upperlevel effects are only significant in the period from -24 to $-9 \mathrm{~h}$. The midlevel negative contribution indicates that the cyclone is influenced by the midlevel cold-air advection, as reported by Rausch and Smith (1996). The profiles of temperature advection and its Laplacian, shown in Figs. $12 \mathrm{c}$ and $12 \mathrm{~d}$, demonstrate that the upper positive contribution is mainly due to the advection of warm air over the cyclone center. The upper-level warm-air advection is related to deep tropopause intrusion, in accordance with the results of Hirschberg and Fritsch (1991), as warm stratospheric air in the westerly and southwesterly winds is positioned upstream from the surface cyclone center. Figure $12 \mathrm{~d}$ also reveals that the substantial low-level forcing is a result of the Laplacian (or distribution) of the temperature advection, which takes on larger values in the lower troposphere. Because tendencies attributable to indirect effects (Fig. 11e) are larger in the upper levels, the total effect of the temperature advection term in generating $950-\mathrm{hPa} \mathrm{CGV}$ is to force divergence in the lower levels (Fig. 11f).

Latent heat release in the ascending air is located in a layer extending from 800 to $600 \mathrm{hPa}$ over the cyclone center and increases the 950-hPa CGV throughout development (Fig. 13a). The vertical motion induced by latent heating produces relatively strong adiabatic cooling in the troposphere below $600 \mathrm{hPa}$ (Fig. 13b). The total effect of this term (Fig. 13c) is therefore to increase the $\mathrm{CGV}$ through the positive contributions in 

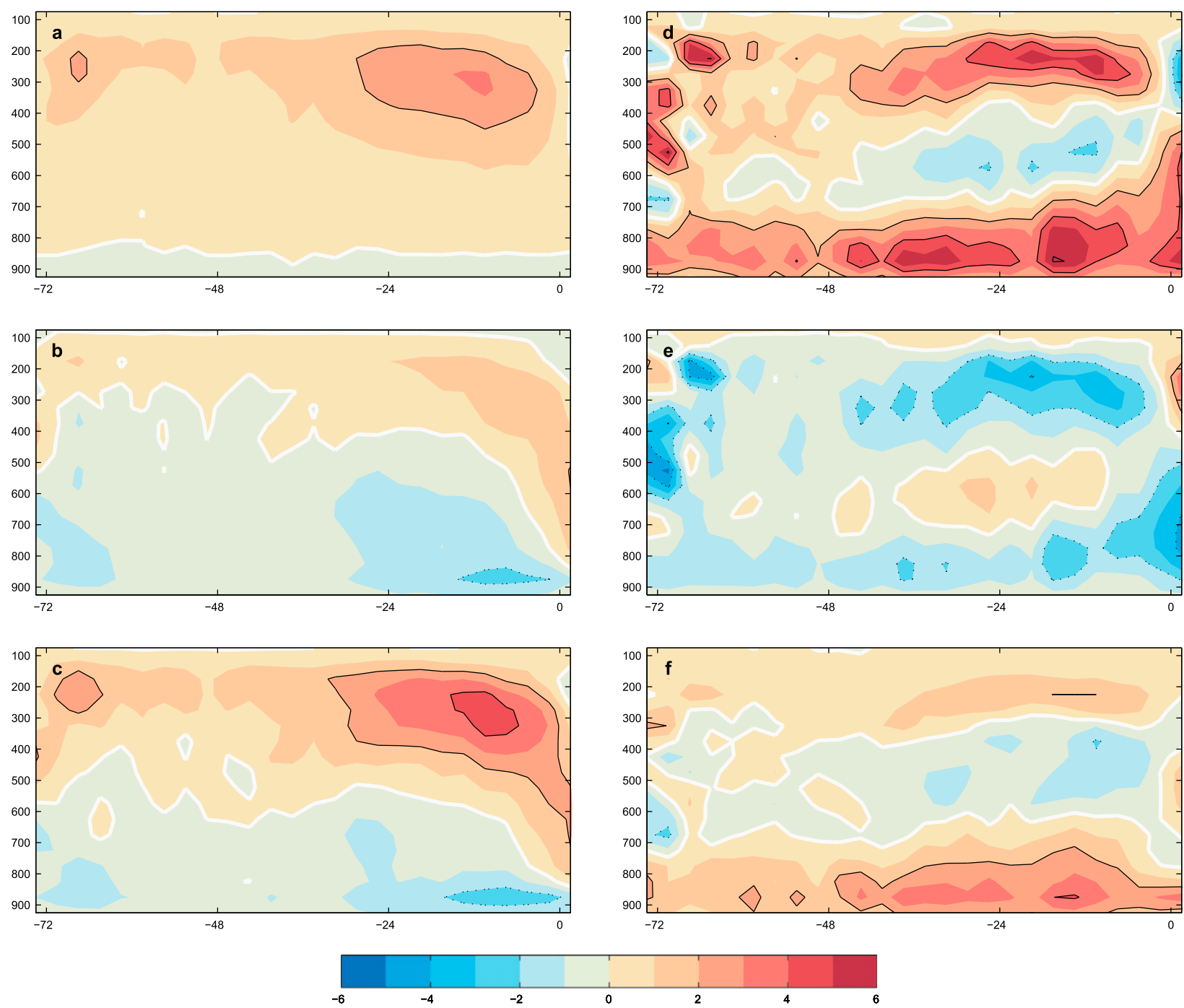

FIG. 11. Time-pressure cross-sectional profiles $\left(10^{-10} \mathrm{~s}^{-2}\right)$ of the (a) direct, (b) indirect, and (c) total effects of the vorticity advection and the (d) direct, (e) indirect, and (f) total effects of the temperature advection. The vertical axis is the pressure (hPa), and the horizontal axis is the time (h) before peak intensity. The zero contour is in white.

the $800-600-\mathrm{hPa}$ layer and to decrease it through adiabatic cooling below $800 \mathrm{hPa}$. The former is due to the fact that sources of latent heating aloft force ascending air and adiabatic cooling below $800 \mathrm{hPa}$ where the latent heating is nearly zero (Deveson et al. 2002). The vertical profiles of the ageostrophic vorticity tendency term are only notable at the end of the development where the negative ageostrophic vorticity tendencies are prominent (Fig. 13d). The direct and indirect effects possess the same sign, which results in large total positive values at lower levels before the time of the peak intensity (Figs. 13e,f). The vertical profiles of the friction term (not shown) indicate that friction reduces the $950-\mathrm{hPa}$ CGV, largely through its indirect effects. Similar to the ageostrophic vorticity tendency term, the direct and indirect effects have the same sign. The profile of the total friction term shows a maximum at around $850 \mathrm{hPa}$, which is typically the top of the boundary layer.

Figure 14 shows the vertical profile made by summing all the $\mathrm{Z}-\mathrm{O}$ forcing terms. The summed direct effects (Fig. 14a) reflect the importance of both the upper- and lower-level processes in the generation of the 950-hPa CGV at the cyclone center. Through the incipient stage, the influence of the low-level processes is slightly larger than that of the upper-level processes. This is a characteristic that all DAY1, DAY2, and DAY3 subsets also share during their development (not shown). The summed indirect effects (Fig. 14b) act to dissipate the cyclonic circulation, primarily through low-level adiabatic cooling. The summed total effects 

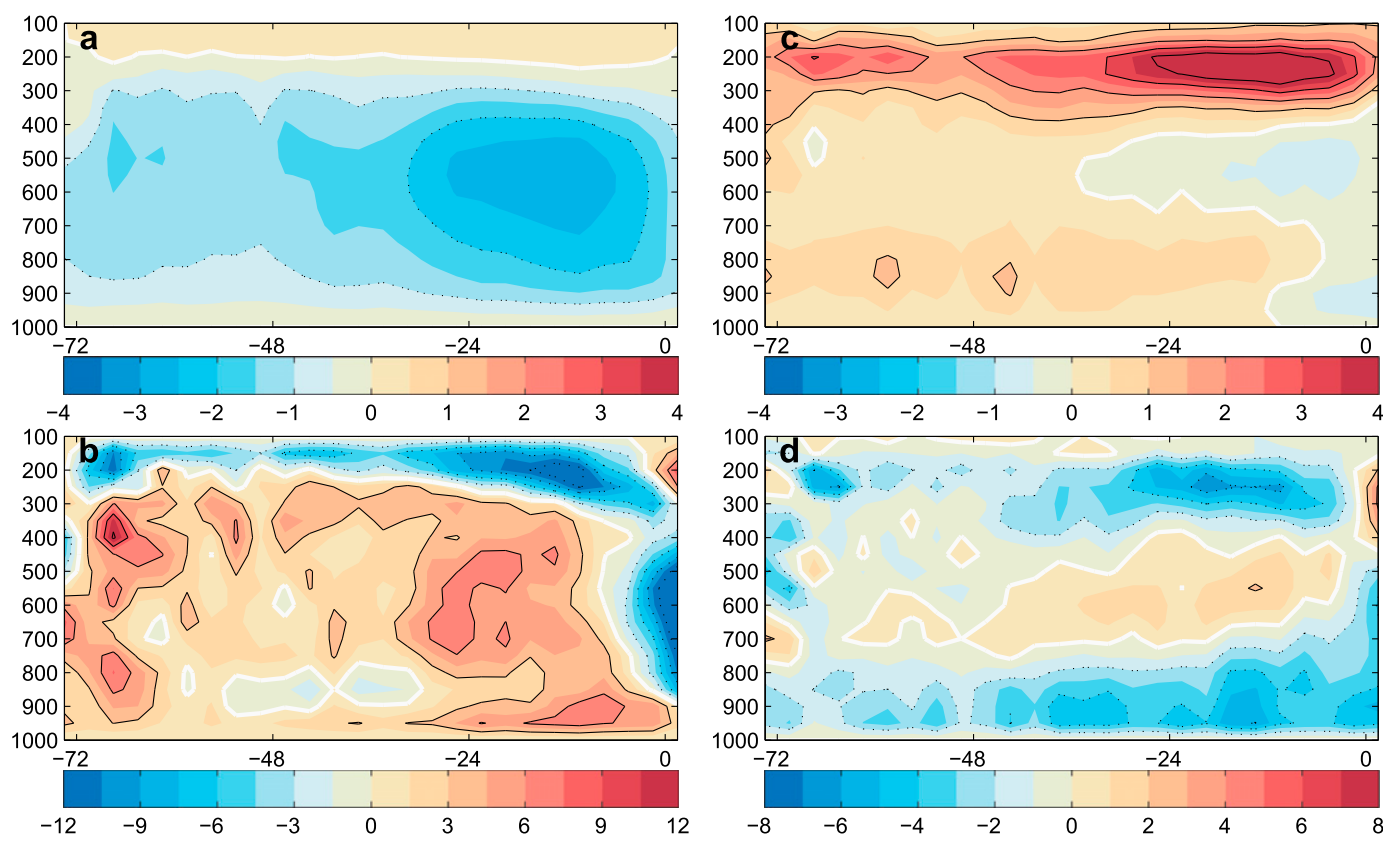

FIG. 12. Time-pressure cross section of (a) the vertical motion induced by the horizontal vorticity advection $\left(10^{-3} \mathrm{~Pa} \mathrm{~s}^{-1}\right)$ and (b) its Laplacian $\left(10^{-16} \mathrm{~s}^{-1} \mathrm{~m}^{-2}\right)$ and (c) the horizontal temperature advection $\left(10^{-4} \mathrm{~s}^{-2}\right)$ and (d) its Laplacian $\left(10^{-15} \mathrm{~s}^{-2}\right)$ for the same period in Fig. 11. The white line shows the zero values.

(Fig. 14c) are thus focused at the upper levels in both the incipient and mature stages. This emphasizes that upper-level dynamics play a dominant role in the evolution and development of the surface-low systems. Note that, at the end of development, production of 950-hPa CGV occurs mainly at middle and low levels $(500-850 \mathrm{hPa})$.

\section{e. Contributions for the entire developing stage}

We analyzed the case-to-case variability of contributions at each time of the development in the previous section. It would be of additional interest to assess the importance and variability of mean contributions of each Z-O forcing term. A mean-contribution value for each cyclone is defined as the average of the contributions by the individual forcing terms at the cyclone center for the cyclone of interest during the entire period of development. This provides a measure of the variability within the cyclone composite. Figure 15 presents the range of the mean-contribution values and Table 1 displays the corresponding percentages of its averaged quantities.

The largest variability in the direct (Fig. 15a) and indirect (Fig. 15b) effects is seen in the temperature advection and latent heating terms. The difference between the mean and median values indicates that the role of latent heating is even more case dependent. We see that the temperature advection term accounts for a large portion of the indirect contributions, reflecting the strong vertical motions and associated adiabatic cooling induced by the advection of warm air over the cyclone center. The induced cooling effect is weaker than the directly forced warming, a result seen in previous works (e.g., Zhang et al. 1999). However, the total effect of each Z-O forcing term on $950-\mathrm{hPa}$ GV tendencies (Fig. 15c) shows that the large negative influence of the indirect effects of the temperature and latent heating terms results in a smaller total effect compared to that for the vorticity advection term. The direct influence of ageostrophic vorticity tendency forcing on 950-hPa GV tendencies is smaller. When the positive but nearly zero indirect effect is added to the direct effect, it yields a larger total effect. Friction is shown to have a negative but secondary influence on the development, though its negative indirect effect leads to a remarkable negative total contribution. The composite effect of sensible heating in changing the $950-\mathrm{hPa} \mathrm{GV}$ is very small.

\section{Summary and conclusions}

The composite contributions of dynamic and thermodynamic forcing mechanisms to near-surface $(950 \mathrm{hPa})$ cyclone development were examined for the 100 most intense winter, long-lived, and well-organized low pressure systems over the North Atlantic in the period 

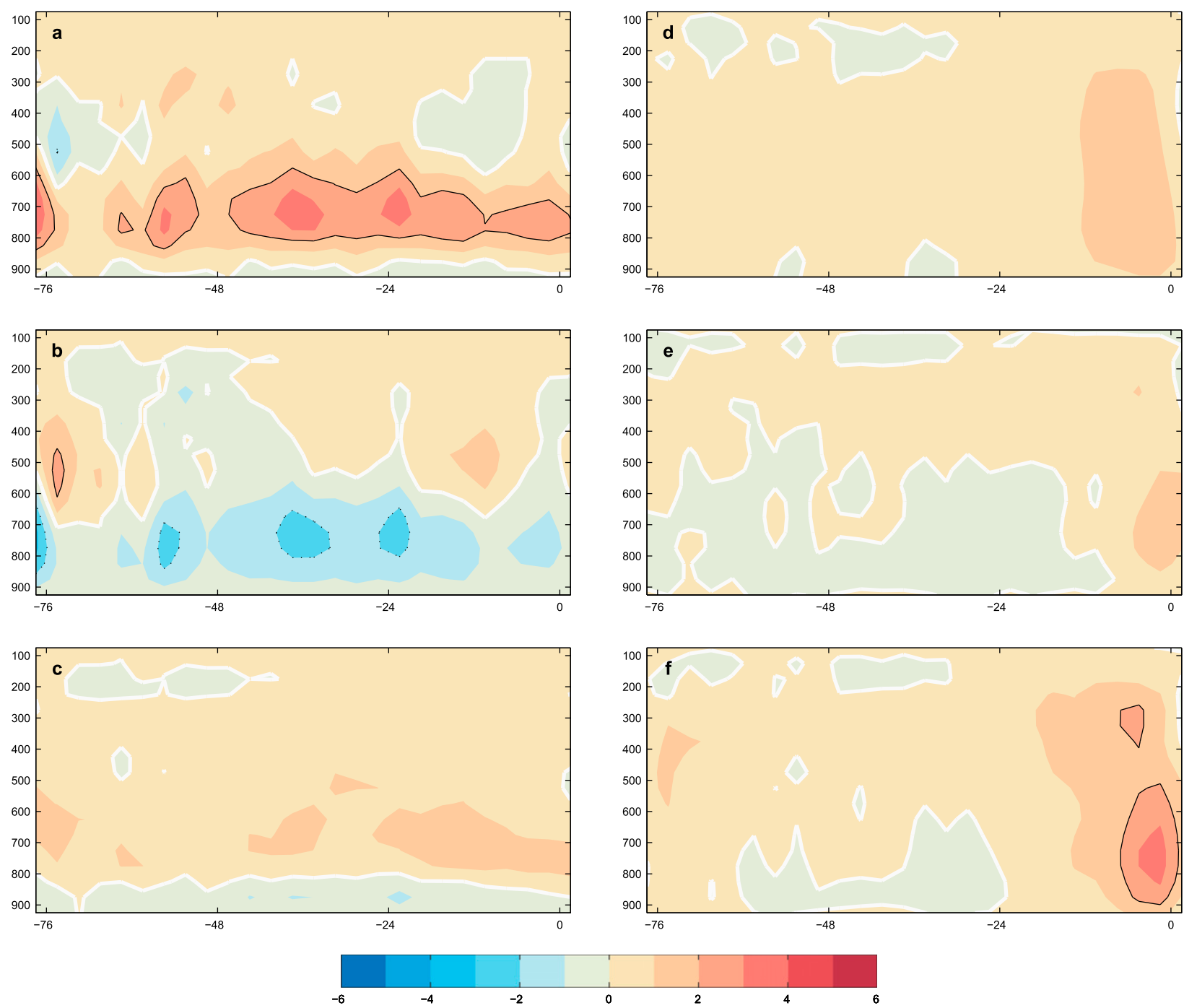

FIG. 13. As in Fig. 11, but for the (a) direct, (b) indirect, and (c) total effect of the latent heating and the (d) direct, (e) indirect, and (f) total effects attributed to the ageostrophic vorticity tendency.

1979-2009. We used a partitioning technique to combine the omega equation and $\mathrm{Z}-\mathrm{O}$ equation. The derived paired-tendency equation consists of six components, which correspond to six physical processes, and provides the basis to examine the direct effects of dynamic and thermodynamic forcing terms, the indirect effect on the adiabatic forcing term, and the total (direct plus indirect) effect of each forcing mechanism to the production or dissipation of 950-hPa geostrophic vorticity. To examine the evolution of cyclones that experience genesis at different times before the peak intensity, we constructed constant-population subcomposites DAY1, DAY2, and DAY3 and analyzed their features. DAY1, DAY2, and DAY3 are cyclones that develop at least 1,2 , and 3 or more days before the peak intensity, respectively.
Our composite results show that the DAY1 cyclones experience an explosive and short development phase, while the DAY2 and DAY3 cyclones show a weak evolution at the beginning of their development. However, all of the subcomposites share similar characteristics in terms of the related forcing mechanisms in the $\mathrm{Z}-\mathrm{O}$ equation. The major direct contributors are temperature advection, vorticity advection, and latent heating. This suggests that, although a large number of the selected events were dominated by baroclinic processes, the diabatic contributions also accounted for a considerable part of the cyclone evolution (e.g., Smith et al. 1984; Tsou et al. 1987; Fosdick and Smith 1991; Fink et al. 2012). The relatively large direct forcing by temperature advection for cyclones over the North 

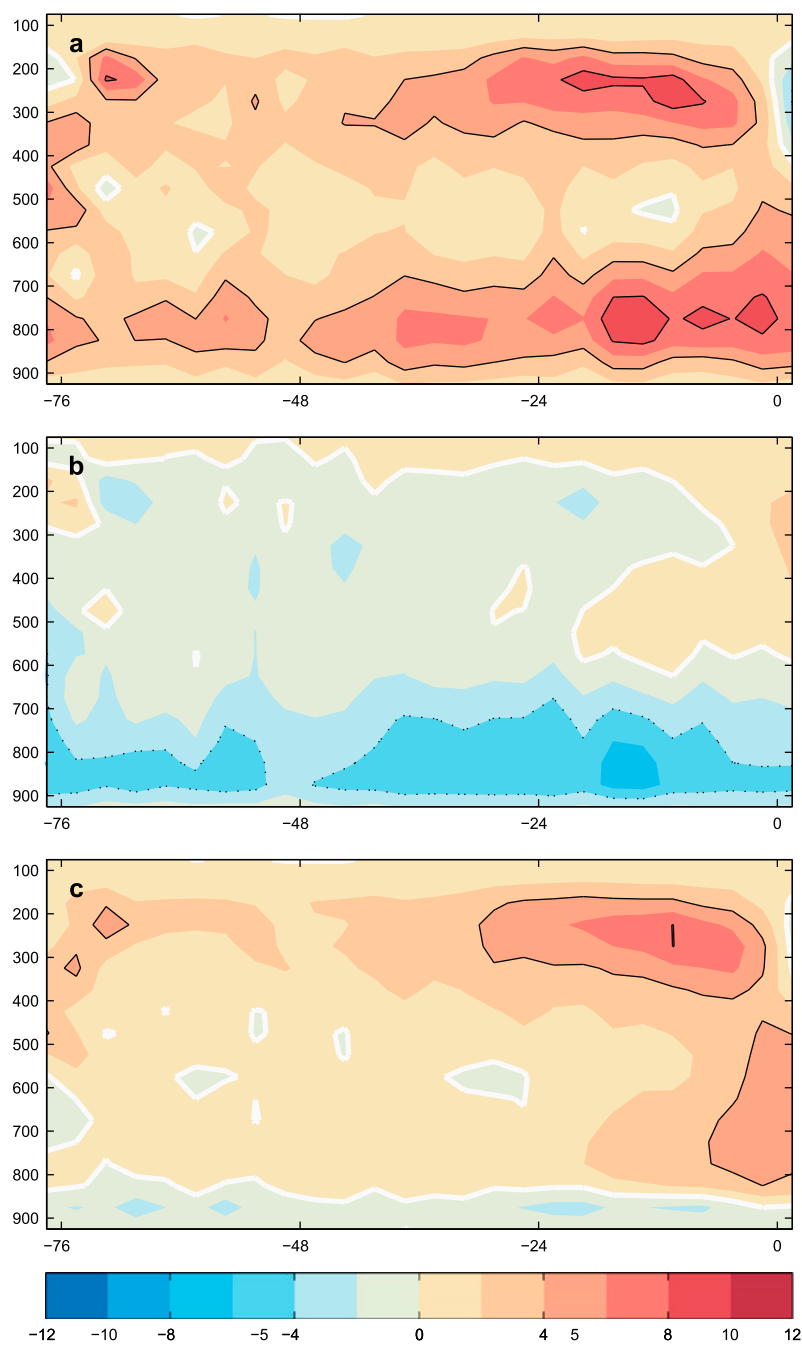

FIG. 14. As in Fig. 11, but for the summed (a) direct, (b) indirect, and (c) total effects of all $\mathrm{Z}-\mathrm{O}$ forcing terms.

Atlantic, which was also reported by Yoshida and Asuma (2004) for northwestern Pacific cyclones, is not seen for land cyclones (Rolfson and Smith 1996), where the vorticity advection term is the major contributor to cyclone deepening. The case studies by Lupo et al. (1992), Rausch and Smith (1996), and Walthorn and Smith (1998) also show that temperature advection has the largest influence on the development of North Atlantic ETCs.

Interestingly, case-to-case variability was notable. However, the variabilities were smaller for the total contributions (e.g., Fig. 15). Based on this result, we come to the conclusion that the total effect diagnostics introduced by means of the $\mathrm{Z}-\mathrm{O}$ and omega equations are useful to identify the dynamically consistent characteristics of low pressure evolution in midlatitudes. Based on the total contributions, we found that the
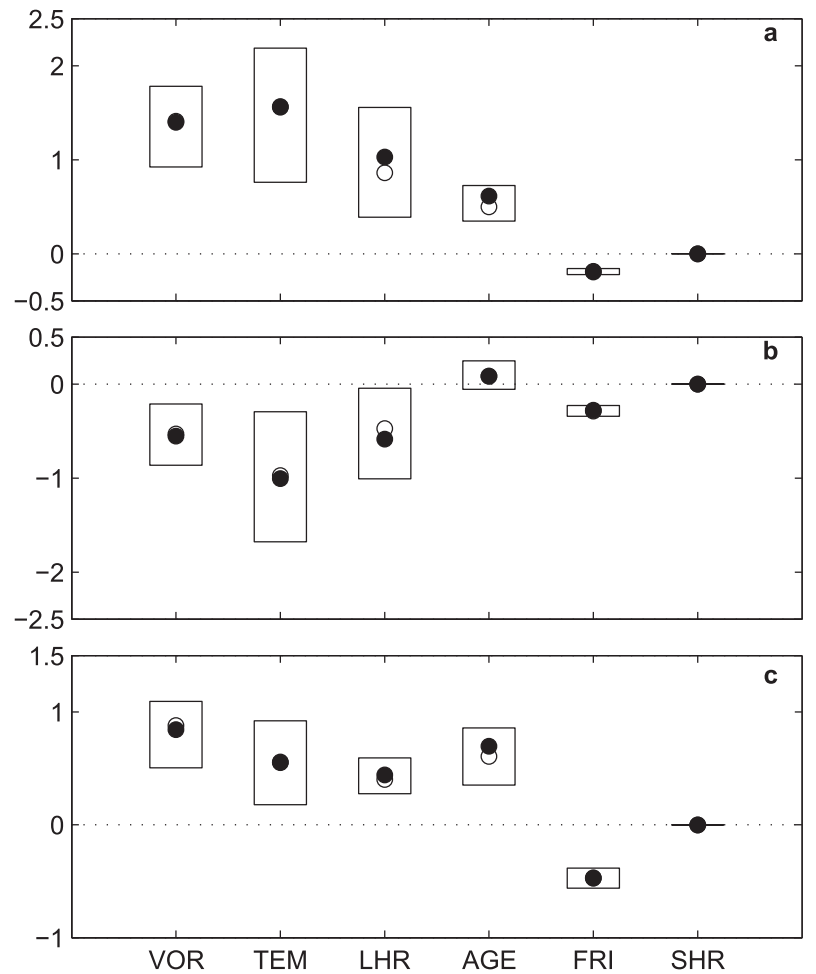

FIG. 15. (a) Direct, (b) indirect, and (c) total mean contributions $\left(10^{-9} \mathrm{~s}^{-2}\right)$ to the $950-\mathrm{hPa} \mathrm{GV}$ tendency at the cyclone center for the entire development phase attributed to the vorticity advection (VOR), temperature advection (TEM), latent heat release (LHR), ageostrophic vorticity tendency (AGE), friction (FRI), and sensible heating (SHR) terms. Boxes are the 25th-75th percentiles. White and black-filled circles show median and mean values, respectively.

vorticity advection is the major forcing process in our composite, the influence of ageostrophic vorticity tendency term on $950 \mathrm{hPa}-\mathrm{GV}$ tendencies is considerable, and the effect of friction in the boundary layer is as important as the other forcing terms. The ageostrophic vorticity tendency term is rather a correction term in the $\mathrm{Z}-\mathrm{O}$ equation, as its presence implies that not all of the forcing acts on the geostrophic vorticity. The technique used by Lupo (2002) to estimate the ageostrophic

TABLE 1. Percentage of averaged direct, indirect, and total mean contributions to the $950-\mathrm{hPa} \mathrm{GV}$ tendency at the cyclone center for the entire development phase attributed to the vorticity advection, temperature advection, latent heating, ageostrophic vorticity tendency, friction, and sensible heating terms. The larger values are boldface. Positive (negative) signs correspond to the production (dissipation) of 950-hPa GV.

\begin{tabular}{lcccrrc}
\hline \hline & VA & TA & LH & AG & FR & SH \\
\hline Direct & $+\mathbf{2 9} \%$ & $+\mathbf{3 3} \%$ & $+\mathbf{2 2} \%$ & $+12 \%$ & $-4 \%$ & $-0.01 \%$ \\
Indirect & $\mathbf{- 2 2} \%$ & $-\mathbf{4 0} \%$ & $-\mathbf{2 4} \%$ & $+3 \%$ & $-11 \%$ & $-0.01 \%$ \\
Total & $+\mathbf{2 8} \%$ & $+18 \%$ & $+15 \%$ & $+\mathbf{2 3} \%$ & $-16 \%$ & $-0.20 \%$ \\
\hline
\end{tabular}


tendency term in the Z-O equation implies, however, that some portion of the ageostrophic vorticity tendencies are due to the vertical motion induced by other forcing terms. Therefore, one can claim that this portion acts as a forcing and the remaining acts as a correction term.

In general, the incipient stage involves strong contributions from low-level warm-air advection and midlevel latent heating, whereas the evolution to the mature stage is associated with the strong upper-level cyclonic vorticity advection and warm-air advection. The sum of the direct profiles (Fig. 14a) demonstrates that genesis is forced by lower-tropospheric forcing for a fairly large number of cyclone events. This is similar to one of the preconditions associated with Petterssen and Smebye's (1971) type-A cyclogenesis. However, after including the counteractive indirect effects of adiabatic cooling (Fig. 14b), the total vertical profiles (Fig. 14c) indicate that the upper-air-level processes are the main forcing mechanisms that drive intensification of the ETC systems. Therefore, we conclude that our composite cyclone, on average, underwent type-B cyclogenesis. All cyclones used in our composites were generated over the western North Atlantic. Dacre and Gray (2009) show that this is a region where cyclogenesis is often forced by upper-level quasigeostrophic mechanisms.

Another interesting finding is related to the dynamics at the end of the development. The composite profiles reveal that production of cyclonic circulation at the time of the strongest $950-\mathrm{hPa} \mathrm{GV}$ tendency is associated with upperlevel forcing mechanisms. But, after that, the midlevel processes induce divergence that further deepens the surface-low system. This is mainly due to three positive contributions: the release of latent heat, the negative ageostrophic vorticity tendencies, and the indirect effect of cyclonic vorticity advection. The latter occurs because convergence forced by adiabatic cooling may yield divergence in areas near to the ascending air, which eventually increases $950-\mathrm{hPa} \mathrm{CGV}$ at the cyclone center.

One of the issues in employing the $\mathrm{Z}-\mathrm{O}$ equation is the larger tendencies when compared to reanalysis (e.g., Lupo 2002). To assess the possible sources of the differences, we compared MERRA's vertical motion field to the one calculated by the omega equation [Eq. (2)]. Despite the high correlations and comparable rootmean-square values between two vertical motion fields, low-level $(850 \mathrm{hPa})$ adiabatic cooling was weaker when obtained from the calculated vertical motion. Using MERRA's omega field, the overestimation of the 950-hPa GV tendencies were reduced, especially at the end of the development phase.

Acknowledgments. This work was financed by the Norwegian Research Council SFF grant to the Bjerknes
Centre for Climate Research and the Norwegian Research Council project EarthClim. We thank Professor Joe Lacasce, Professor Gudrun Magnusdottir, and Dr Stefan Sobolowski for their suggestions regarding the presentation of results and displaying of figures. The authors are likewise grateful to Professor Emeritus Phillip Smith for his insight and comments on the manuscript and Dr. Kevin Hodges for providing the cyclone trajectories. MERRA data used in this study have been provided by the Global Modeling and Assimilation Office (GMAO) at NASA Goddard Space Flight Center through the NASA GES DISC online archive.

\section{REFERENCES}

Azad, R., and A. Sorteberg, 2009: A diagnosis of warm-core and cold-core extratropical cyclone development using the Zwack-Okossi equation. Atmos. Sci. Lett., 10, 220-225, doi:10.1002/asl.244.

— and - 2014: The vorticity budgets of North Atlantic winter extratropical cyclones life cycle in MERRA. Part II: Decaying phase. J. Atmos. Sci., 71, 3129-3143, doi:10.1175/ JAS-D-13-0266.1.

Bengtsson, L., K. I. Hodges, M. Esch, N. Keenlyside, L. Kornblueh, J.-J. Luo, and T. Yamagata, 2007: How may tropical cyclones change in a warmer climate? Tellus, 59A, 539-561, doi:10.1111/ j.1600-0870.2007.00251.x.

, - - and N. Keenlyside, 2009: Will extratropical storms intensify in a warmer climate? J. Climate, 22, 2276-2301, doi:10.1175/2008JCLI2678.1.

Boutle, I. A., R. J. Beare, S. E. Belcher, and R. S. Plant, 2007: A note on boundary-layer friction in baroclinic cyclones. Quart. J. Roy. Meteor. Soc., 133, 2137-2141, doi:10.1002/qj.179.

Caron, J.-F., M. K. Yau, S. Laroche, and P. Zwack, 2007: The characteristics of key analysis errors. Part I: Dynamical balance and comparison with observations. Mon. Wea. Rev., 135, 249-266, doi:10.1175/MWR3285.1.

Carrera, M. L., J. R. Gyakum, and D.-L. Zhang, 1999: A numerical case study of secondary marine cyclogenesis sensitivity to initial error and varying physical processes. Mon. Wea. Rev., 127, 641660, doi:10.1175/1520-0493(1999)127<0641:ANCSOS>2.0.CO;2.

Catto, J. L., L. C. Shaffrey, and K. I. Hodges, 2010: Can climate models capture the structure of extratropical cyclones? J. Climate, 23, 1621-1635, doi:10.1175/2009JCLI3318.1.

Cullather, R. I., and M. G. Bosilovich, 2011: The moisture budget of the polar atmosphere in MERRA. J. Climate, 24, 28612879, doi:10.1175/2010JCLI4090.1.

Dacre, H. F., and S. L. Gray, 2009: The spatial distribution and evolution characteristics of North Atlantic cyclones. Mon. Wea. Rev., 137, 99-115, doi:10.1175/2008MWR2491.1.

, M. K. Hawcroft, M. A. Stringer, and K. I. Hodges, 2012: An extratropical cyclone atlas: A tool for illustrating cyclone structure and evolution characteristics. Bull. Amer. Meteor. Soc., 93, 1497-1502, doi:10.1175/BAMS-D-11-00164.1.

Davis, C. A., M. T. Stoelinga, and Y.-H. Kuo, 1993: The integrated effect of condensation in numerical simulations of extratropical cyclogenesis. Mon. Wea. Rev., 121, 2309-2330, doi:10.1175/1520-0493(1993)121<2309:TIEOCI > 2.0.CO;2.

Deveson, A. C. L., K. A. Brwoning, and T. D. Hewson, 2002: A classification of FASTEX cyclones using a height-attributable 
quasi-geostrophic vertical-motion diagnostic. Quart. J. Roy. Meteor. Soc., 128, 93-117, doi:10.1256/00359000260498806.

Fink, A. H., S. Pohle, J. G. Pinto, and P. Knippertz, 2012: Diagnosing the influence of diabatic processes on the explosive deepening of extratropical cyclones. Geophys. Res. Lett., 39, L07803, doi:10.1029/2012GL051025.

Fosdick, E. K., and P. J. Smith, 1991: Latent heat release in an extratropical cyclone that developed explosively over the southeastern United States. Mon. Wea. Rev., 119, 193-207, doi:10.1175/1520-0493(1991)119<0193:LHRIAE > 2.0.CO;2.

Haltiner, G. J., and R. T. Williams, 1980: Numerical Prediction and Dynamical Meteorology. 2nd ed., John Wiley \& Sons, 477 pp.

Hirschberg, P. A., and J. M. Fritsch, 1991: Tropopause undulations and the development of extratropical cyclones. Part I: Overview and observations from a cyclone event. Mon. Wea. Rev., 119, 496-517, doi:10.1175/1520-0493(1991)119<0496: TUATDO $>2.0 . \mathrm{CO} ; 2$.

Hodges, K. I., 1999: Adaptive constraints for feature tracking. Mon. Wea. Rev., 127, 1362-1373, doi:10.1175/ 1520-0493(1999)127<1362:ACFFT > 2.0.CO;2.

, R. W. Lee, and L. Bengtsson, 2011: A comparison of extratropical cyclones in recent reanalyses ERA-Interim, NASA MERRA, NCEP CFSR, and JRA-25. J. Climate, 24, 48884906, doi:10.1175/2011JCLI4097.1.

Holton, J. R., 2004: An Introduction to Dynamic Meteorology. 4th ed. International Geophysics Series, Vol. 88, Academic Press, $535 \mathrm{pp}$.

Kuwano-Yoshida, A., and T. Enomoto, 2013: Predictability of explosive cyclogenesis over the northwestern Pacific region using ensemble reanalysis. Mon. Wea. Rev., 141, 3769-3785, doi:10.1175/MWR-D-12-00161.1.

Lupo, A. R., 2002: Ageostrophic forcing in a height tendency equation. Mon. Wea. Rev., 130, 115-126, doi:10.1175/ 1520-0493(2002)130<0115:AFIAHT >2.0.CO;2.

—, P. J. Smith, and P. Zwack, 1992: A diagnosis of the explosive development of two extratropical cyclones. Mon. Wea. Rev., 120, 1490-1523, doi:10.1175/1520-0493(1992)120<1490: ADOTED $>2.0 . \mathrm{CO} ; 2$

Morris, W. E., and P. J. Smith, 2001: Cyclolysis: A diagnosis of two extratropical cyclones. Mon. Wea. Rev., 129, 2714-2729, doi:10.1175/1520-0493(2001)129<2714:CADOTE >2.0.CO;2.

Pagé, C., L. Fillion, and P. Zwack, 2007: Diagnosing summertime mesoscale vertical motion: Implications for atmospheric data assimilation. Mon. Wea. Rev., 135, 2076-2094, doi:10.1175/ MWR3371.1.

Parsons, K. E., and P. J. Smith, 2004: An investigation of extratropical cyclone development using a scale-separation technique. Mon. Wea. Rev., 132, 956-974, doi:10.1175/ 1520-0493(2004)132<0956:AIOECD>2.0.CO;2.

Pauley, P. M., and S. J. Nieman, 1992: A comparison of quasigeostrophic and nonquasigeostrophic vertical motions for a model-simulated rapidly intensifying marine extratropical cyclone. Mon. Wea. Rev., 120, 1108-1134, doi:10.1175/ 1520-0493(1992)120<1108:ACOQAN>2.0.CO;2.

Petterssen, S., and S. J. Smebye, 1971: On the development of extratropical cyclones. Quart. J. Roy. Meteor. Soc., 97, 457-482, doi:10.1002/qj.49709741407.

Räisänen, J., 1997: Height tendency diagnostics using a generalized omega equation, the vorticity equation, and a nonlinear balance equation. Mon. Wea. Rev., 125, 1577-1597, doi:10.1175/ 1520-0493(1997)125<1577:HTDUAG > 2.0.CO;2.
Rausch, R. L. M., and P. J. Smith, 1996: A diagnosis of a modelsimulated explosively developing extratropical cyclone. Mon Wea. Rev., 124, 875-904, doi:10.1175/1520-0493(1996)124<0875: ADOAMS $>2.0 . \mathrm{CO} ; 2$.

Rienecker, M. M., and Coauthors, 2011: MERRA: NASA's ModernEra Retrospective Analysis for Research and Applications. J. Climate, 24, 3624-3648, doi:10.1175/JCLI-D-11-00015.1.

Rolfson, D. M., and P. J. Smith, 1996: A composite diagnosis of synoptic-scale extratropical cyclone development over the United States. Mon. Wea. Rev., 124, 1084-1099, doi:10.1175/ 1520-0493(1996)124<1084:ACDOSS > 2.0.CO;2.

Sanders, F., and J. R. Gyakum, 1980: Synoptic-dynamic climatology of the "bomb." Mon. Wea. Rev., 108, 1589-1606, doi:10.1175/1520-0493(1980)108<1589:SDCOT>2.0.CO;2.

Shapiro, R., 1970: Smoothing, filtering, and boundary effects. Rev. Geophys., 8, 359-387, doi:10.1029/RG008i002p00359.

Sinclair, M. R., and M. J. Revell, 2000: Classification and composite diagnosis of extratropical cyclogenesis events in the southwest Pacific. Mon. Wea. Rev., 128, 1089-1105, doi:10.1175/ 1520-0493(2000)128<1089:CACDOE > 2.0.CO;2.

Smith, P. J., 2000: The importance of the horizontal distribution of heating during extratropical cyclone development. Mon. Wea. Rev., 128, 3692-3694, doi:10.1175/1520-0493(2000)128<3692: TIOTHD $>2.0 . C O ; 2$.

_ , P. M. Dare, and S.-J. Un, 1984: The impact of latent heat release on synoptic-scale vertical motions and the development of an extratropical cyclone system. Mon. Wea Rev., 112, 2421-2430, doi:10.1175/1520-0493(1984)112<2421: TIOLHR $>2.0 . \mathrm{CO} ; 2$.

Sorteberg, A., and J. Walsh, 2008: Seasonal cyclone variability at $70^{\circ} \mathrm{N}$ and its impact on moisture transport into the Arctic. Tellus, 60A, 570-586, doi:10.1111/j.1600-0870.2008.00314.x.

Strahl, J. L. S., and P. J. Smith, 2001: A diagnostic study of an explosively developing extratropical cyclone and an associated 500-hPa trough merger. Mon. Wea. Rev., 129, 2310-2328, doi:10.1175/1520-0493(2001)129<2310:ADSOAE > 2.0.CO;2.

Tsou, C.-H., P. J. Smith, and P. M. Pauley, 1987: A comparision of adiabatic and diabatic forcing in an intense extratropical cyclone system. Mon. Wea. Rev., 115, 763-786, doi:10.1175/ 1520-0493(1987)115<0763:ACOAAD > 2.0.CO;2.

Vasilj, J. M., and P. J. Smith, 1997: A comparison of extended and quasigeostrophic dynamics for a case of small-Rossby number extratropical cyclone development. Mon. Wea Rev., 125, 3347-3356, doi:10.1175/1520-0493(1997)125<3347: ACOEAQ $>2.0 . \mathrm{CO} ; 2$.

Walthorn, K. D., and P. J. Smith, 1998: The dynamics of an explosively developing cyclone simulated by a general circulation model. Mon. Wea. Rev., 126, 2764-2781, doi:10.1175/ 1520-0493(1998)126<2764:TDOAED > 2.0.CO;2.

Yoshida, A., and Y. Asuma, 2004: Structures and environment of explosively developing extratropical cyclones in the northwestern Pacific region. Mon. Wea. Rev., 132, 1121-1142, doi:10.1175/1520-0493(2004)132<1121:SAEOED>2.0.CO;2.

Zhang, D.-L., E. Radeva, and J. Gyakum, 1999: A family of frontal cyclones over the western Atlantic Ocean. Part II: Parameter studies. Mon. Wea. Rev., 127, 1745-1760, doi:10.1175/ 1520-0493(1999)127<1745:AFOFCO > 2.0.CO;2.

Zwack, P., and B. Okossi, 1986: A new method for solving the quasi-geostrophic omega equation by incorporating surface pressure tendency data. Mon. Wea. Rev., 114, 655-666, doi:10.1175/1520-0493(1986)114<0655:ANMFST>2.0.CO;2. 